\title{
Satellite soil moisture data assimilation impacts on modeling weather variables and ozone in the southeastern US - Part 2: Sensitivity to dry deposition parameterizations
}

\author{
Min Huang, , , James H. Crawford ${ }^{2}$, Gregory R. Carmichael ${ }^{3}$, Kevin W. Bowman ${ }^{4}$, Sujay V. Kumar ${ }^{5}$, \\ 5 and Colm Sweeney 6 \\ ${ }^{1}$ College of Science, George Mason University, Fairfax, VA, USA \\ ${ }^{2}$ NASA Langley Research Center, Hampton, VA, USA \\ ${ }^{3}$ College of Engineering, The University of Iowa, Iowa City, IA, USA \\ ${ }^{4}$ Jet Propulsion Laboratory, California Institute of Technology, Pasadena, CA, USA \\ $10{ }^{5}$ NASA Goddard Space Flight Center, Greenbelt, MD, USA \\ ${ }^{6}$ NOAA Earth System Research Laboratory Global Monitoring Division, Boulder, CO, USA \\ aNow also visiting: National Centers for Environmental Prediction, College Park, MD, USA
}

Correspondence to: Min Huang (mhuang10@gmu.edu)

Abstract. Ozone $\left(\mathrm{O}_{3}\right)$ dry deposition is a major $\mathrm{O}_{3}$ sink. Realistically representing this process in models is important for

15 accurately simulating $\mathrm{O}_{3}$ concentrations and exceedances, as well as assessing the $\mathrm{O}_{3}$ impacts on human and ecosystem health. As a follow-up study of Huang et al. (2021), soil moisture (SM) data from NASA's Soil Moisture Active Passive mission are assimilated into the Noah-Multiparameterization land surface model within the NASA Land Information System framework, semicoupled with Weather Research and Forecasting model with online Chemistry regional-scale simulations covering the southeastern US. Major changes in the used modeling system include enabling the dynamic vegetation option,

20 adding the irrigation process, and updating the $C_{H}$ (i.e., surface exchange coefficient for heat) scheme. Two different dry deposition schemes are implemented, i.e., the Wesely scheme and a "dynamic" scheme, in the latter of which dry deposition parameterization is coupled with photosynthesis and vegetation dynamics. It is demonstrated that, when the "dynamic" scheme is applied, the modeled $\mathrm{O}_{3}$ dry deposition velocities as well as the total, stomatal and cuticular $\mathrm{O}_{3}$ fluxes are overall larger and 2-3 times more sensitive to the SM changes due to the data assimilation (DA). We also highlight that, the configuration of the SM factor controlling stomatal resistance (i.e., the $\beta$ factor which presents dependencies on soil type and hydrological regime) can strongly affect the quantitative results. Referring to multiple observation and observation-derived evaluation datasets, which may be associated with variable extents of uncertainty, the model performance of vegetation, surface fluxes, weather, and surface $\mathrm{O}_{3}$ concentrations, shows mixed responses to the DA, some of which display land cover dependency. Finally, using model-derived concentration- and flux-based policy relevant $\mathrm{O}_{3}$ metrics as well as their matching exposure-response functions, the relative biomass/crop yield losses for several types of vegetation/crops are estimated to be within a wide range below $20 \%$. Their sensitivities to the model's dry deposition scheme and the implementation of SM DA are discussed. 


\section{Introduction}

35 Ground-level ozone $\left(\mathrm{O}_{3}\right)$ is a regulated secondary air pollutant harmful to human and ecosystem health (Fleming et al., 2018; Mills et al., 2018a,b). It is closely connected with $\mathrm{O}_{3}$ at higher altitudes where $\mathrm{O}_{3}$ plays a more important role in the Earth's climate system. To better protect human health and public welfare, in 2015, the US primary and secondary National Ambient Air Quality Standards were lowered from $75 \mathrm{ppbv}$ to $70 \mathrm{ppbv}$, in the format of daily maximum 8-h average (MDA8). Several other $\mathrm{O}_{3}$-exposure based metrics have also been applied or/and proposed to assess $\mathrm{O}_{3}$ impacts on vegetation, such as the accumulated $\mathrm{O}_{3}$ exposure over given thresholds (e.g., SUM40, SUM60, and AOT40), the averaged $\mathrm{O}_{3}$ exposure during daylight hours (e.g., M7 and M12), and the sigmoidal-weighted W126 cumulative exposure (e.g., Fredericksen et al., 1996; van Dingenen et al., 2009; Hemispheric Transport of Air Pollution, 2010, and references therein; Avnery et al., 2011; Hollaway et al., 2012; Huang et al., 2013; Lapina et al., 2014; Mills et al., 2007, 2018a,b). To help comply with the evertightening air quality standards, an improved understanding of the individual processes affecting (near-)surface $\mathrm{O}_{3}$ concentrations and exceedances is demanded. Many $\mathrm{O}_{3}$-related processes are highly sensitive to environmental and/or biophysical conditions (Huang et al., 2021, and references therein). These $\mathrm{O}_{3}$-related processes include dry deposition of $\mathrm{O}_{3}$ and its precursors, which is a major sink for near-surface $\mathrm{O}_{3}$ and depends on dry deposition velocities $\left(\mathrm{V}_{\mathrm{d}}\right)$ and the deposited chemicals' concentrations. As recognized in numerous studies, accurately estimating dry deposition fluxes is critical to understanding $\mathrm{O}_{3}$ budgets and exceedances in the past, present, and future (e.g., Stevenson et al., 2006; Griffiths et al.,

50 2021); it could also contribute to a more reasonable assessment of the $\mathrm{O}_{3}$ impacts on vegetation (e.g., Mills et al., 2011; Lombardozzi et al., 2015; Mills et al., 2018b; Ducker et al., 2018; Ronan et al., 2020), which is relevant to the budgets of other greenhouse gases as well.

Ozone uptake by plants is generally higher in warm/growing seasons and during the daytime when $\mathrm{O}_{3}$ concentrations and $\mathrm{V}_{\mathrm{d}}$

55 values peak. As introduced in Huang et al. (2021) as well as references therein, over the land, surface resistance $R_{c}$, which is composed of stomatal-mesophyll $\left(\mathrm{R}_{\mathrm{s}}-\mathrm{R}_{\mathrm{m}}\right)$, cuticular $\left(\mathrm{R}_{\mathrm{lu}}\right)$, in-canopy, and ground resistance terms, often exerts the strongest effects on the magnitude and variability of $V_{d}$. $V_{d}$ also includes the aerodynamic resistance $\left(R_{a}\right)$ and quasi-laminar sublayer resistance $\left(\mathrm{R}_{\mathrm{b}}\right)$ terms.

60 Soil moisture (SM) and its variability impact $\mathrm{V}_{\mathrm{d}}$ in the following ways: 1) SM can play a key role in controlling the opening and closing of plants' stomata as well as the mesophyll functioning (Egea et al., 2011; Baillie and Fleming, 2019), and thus it can directly affect the $R_{s}$ and $R_{m}$ terms of $V_{d}$; 2) $S M$ is closely linked with vegetation attributes, such as the growing-season aboveground biomass, which is often expressed as leaf area index (LAI) or vegetation optical depth (VOD) and controls the stomatal and cuticular uptake of $\mathrm{O}_{3}$-related species; and 3) SM as well as vegetation conditions can affect multiple $\mathrm{V}_{\mathrm{d}}$ terms

65 through its interactions with other environmental conditions (e.g., temperatures, radiation, precipitation and humidity fields) that modulate these $\mathrm{V}_{\mathrm{d}}$ terms, and such effects are generally stronger over transitional climate zones located between dry and 
wet climates. It is expected that the impacts of $\mathrm{SM}$ on $\mathrm{V}_{\mathrm{d}}$ and atmospheric states through the above-mentioned pathways will continue to increase as the occurrence and severity of droughts, some of which are characterized by surface and/or columnaveraged SM deficits, are projected to increase over many US regions under warmer future environments (Intergovernmental

70 Panel on Climate Change, 2021). Better understanding the potentially enhanced SM dependency of dry deposition and weather conditions under the changing climate is important because $\mathrm{O}_{3}$ stress, together with heat, water, as well as other stresses, can pose more complex threats to plant health than single stress alone (Out-Larbi et al., 2020).

Chemical transport models have long been used to estimate $V_{d}$ values and their responses to climate change. In the widely75 used, empirical Wesely scheme (Wesely, 1989), $V_{d}$ is sensitive to only a few meteorological variables, with SM and plants' physiological effects ignored. In previous studies, Wesely scheme based $V_{d}$ fluxes as well as their various terms from different global and regional chemistry modeling systems were intercompared or/and evaluated with $\mathrm{V}_{\mathrm{d}}$ and $\mathrm{R}_{\mathrm{s}}$ observations from sparsely-distributed sites (e.g., Val Martin et al., 2014; Hardacre et al., 2015; Silva and Heald, 2018; Wu et al., 2018; Lin et al., 2019; Clifton et al., 2020) in terms of their magnitude and variability. Even when similar (Wesely and Wesely-like)

$80 \mathrm{~V}_{\mathrm{d}}$ schemes were applied, various models behaved differently in calculating $\mathrm{V}_{\mathrm{d}}$, reflecting the impacts of land use/land cover (LULC) and meteorological fields which depend on the individual models' configurations (e.g., scales, inputs). Large modelmodel and model-observation discrepancies (i.e., by a factor of 2 or more) have been found in places, suggesting the strong needs of diagnosing and addressing issues in the models' configurations and $\mathrm{V}_{\mathrm{d}}$ parameterizations.

85 Revised or alternative dry deposition schemes have been applied in an increasing number of global- and regional-scale modeling studies. In some of these works, $R_{s}$ is calculated based on multiplicative algorithms in which empirical maximum stomatal conductance is adjusted by multiple factors, including water availability and vegetation attributes (e.g., Anav et al., 2018; Falk and Søvde Haslerud, 2019). In others, $V_{d}$ calculations are coupled with photosynthesis and vegetation phenology (e.g., Val Martin et al., 2014; Lin et al., 2019; Clifton et al., 2020), which in this paper are frequently referred as "dynamic"

90 schemes. Such types of modifications have been the recommended directions for improving the estimates of $\mathrm{V}_{\mathrm{d}}$ as well as the $\mathrm{V}_{\mathrm{d}}$ and $\mathrm{O}_{3}$ responses to climate change, in that they have been demonstrated to be capable of enhancing the dynamics of the modeled $V_{d}$ and reducing their systematic biases. However, results based on such updated $V_{d}$ schemes are still associated with variable extents of uncertainty due to limitations in model parameterizations (related to structures, empirical parameters and stress functions) or/and configurations. In some existing works that applied the "dynamic" schemes, such uncertainty 95 was quantified and addressed by simply scaling the fluxes resulting from the "dynamic" schemes towards flux measurements available at very limited locations during non-recent time periods (e.g., Val Martin et al., 2014). These types of modified $V_{d}$ schemes still require further investigations and optimizations, which can be approached by: 1) quantifying the sensitivities of process-based model variables to SM and other environmental or/and biophysical variables for various LULC and soil types; 2) improving model representations of processes central to SM states and land-atmosphere interactions, such as including irrigation and other human activities, tuning surface exchange coefficient $\left(\mathrm{C}_{\mathrm{H}}\right)$ scheme in land surface models (LSMs), and 
using available observations to constrain (some of) the model land variables; and 3) including a wide range of observations and/or observation-derived carbon, water, and energy fluxes as well as vegetation states in model evaluation for broad geographical regions. Furthermore, it is important to explicitly connect the progress in dry deposition modeling with the impact assessments of $\mathrm{O}_{3}$ and other air pollutants on ecosystem health, productivity, and diversity.

A regional-scale land modeling and SM data assimilation (DA) framework coupled with weather and atmospheric chemistry modeling by the Weather Research and Forecasting model with online Chemistry (WRF-Chem) is implemented in this work. Using this tool, we quantify and discuss the responses of $\mathrm{V}_{\mathrm{d}}$ and its key components as well as $\mathrm{O}_{3}$ concentrations and plant uptake to SM changes due to the DA, for different soil texture, LULC and crop types. The central parts of this work rely on the Noah-Multiparameterization (MP, Niu et al., 2011) LSM with dynamic vegetation that enables the implementation of a modified "dynamic" dry deposition scheme. With this modified scheme, both the indirect (i.e., via changing weather and vegetation fields) and direct effects of SM on dry deposition are considered in this modeling system. Results based on this modified and the WRF-Chem default Wesely schemes are compared and evaluated with independent datasets. As an extended work of Huang et al. (2021), here we continue to focus on the southeastern US during summer 2016 for which

115 period prior Noah- and Wesely-based model calculations were conducted and aircraft observations are available. This manuscript introduces the applied two dry deposition schemes in Section 2. It then presents results from this Noah-MP based modeling system, in comparison with those from Huang et al. (2021) (Sections 3.1-3.2). Discussions on $\mathrm{O}_{3}$ concentrations and fluxes based on all related WRF-Chem simulations are also connected with the assessment of $\mathrm{O}_{3}$ impacts on societies, ecosystem health, and crop yield (Section 3.3). Summary and suggestions on future directions are provided in Section 4.

\section{Methods}

\subsection{Modeling and DA experiments design}

The modeling tools and DA experiment design of this study were largely consistent with the Huang et al. (2021) study: we conducted model simulations over the southeastern US in a semi-coupled Land Information System (LIS)/WRF-Chem system without and with the assimilation of the enhanced SM retrievals from NASA's Soil Moisture Active Passive (SMAP)

125 mission. Two dry deposition schemes were applied in cases without and with the SM DA. The model domain, horizontal and vertical resolutions, atmospheric/land initialization and SM DA methods were adapted from our previous study based on the Noah LSM. Major model input datasets, physics and chemistry schemes were kept similar as before except a few aspects relevant to the upgrade of LSM from Noah to Noah-MP (version 3.6) and the implementation of an irrigation scheme to be introduced in Section 2.2.

Same as in Huang et al. (2021), the LULC and soil texture type inputs of our coupled modeling system were based on the International Geosphere-Biosphere Programme-modified Moderate Resolution Imaging Spectroradiometer and the State Soil 
Geographic datasets, respectively. Crop type data from Monfreda et al. (2008) were used in the irrigation scheme and the assessment of the $\mathrm{O}_{3}$ impacts on vegetation (Figure 1b), which are roughly consistent with the 2016 records from the US Department of Agriculture National Agricultural Statistics Service for several major crops such as maize, soybean and wheat (https://nassgeodata.gmu.edu/CropScape, lass access: 8 November 2021). In Section 3 of this paper, model results are summarized and/or discussed by groups of grid-dominant LULC and soil type that are shown in Figure 1(a;d). The original 20 LULC types were grouped into urban and non-urban areas, and for vegetation-dominant areas, into forests, croplands, and shrub/grasslands, following the criteria introduced in Table S1. The grid-dominant LULC groups for vegetated regions used in our analysis are vastly similar to independently-developed data products, e.g.: a dataset derived from the European Space Agency-Climate Change Initiative Land Cover project (https:/gwis.jrc.ec.europa.eu/apps/country.profile/overview/USA, lass access: 8 November 2021), and the 2016 National Land Cover Database. Urban-dominant grid cells are well aligned with dense population areas (Figure 1c) based on the Gridded Population of the World version 4.11 (NASA Socioeconomic Data and Applications Center, 2018). Grid-scale discrepancies exist between the used LULC input and independent LULC products, which, however, are not anticipated to considerably impact the results averaged by LULC groups. Three groups of soil are highlighted, namely sand/loamy sand, loam and clay. The original sand and loamy sand categories are combined because of their high sand fractions (http://www.soilinfo.psu.edu/index.cgi?soil_data\&conus\&data_cov\&fract\&methods, lass access: 10 December 2021).

\subsection{Physics and configurations of the Noah-MP LSM}

150 The Noah-MP LSM includes a number of improvements from Noah, and one of the enhanced features in Noah-MP is that it contains a separate canopy layer that explicitly computes photosynthetically active radiation, canopy temperature, and related energy, water, and carbon fluxes so that it facilities a dynamic vegetation model. A modified two-stream radiation transfer scheme was used to compute fractions of sunlit and shaded leaves and their absorbed solar radiation. The Ball-Berry type of $R_{S}$ scheme (e.g., Ball et al., 1987) was applied as required by the dynamic vegetation option. When this option is used, green vegetation fraction (GVF) does not come from an input dataset as in Huang et al. (2021) but is related to LAI based on (1):

$$
G V F=1-e^{-0.52 L A I}
$$

Niyogi and Raman (1997) concluded that Ball-Berry along with two other physiological schemes, performed better on $R_{S}$ than the multiplicative Jarvis type which has been frequently used with the prescribed vegetation option. Specifically, it

160 helps better capture the variance in $R_{s}$ and is more responsive to environmental changes. As described in Appendix B of Niu et al. (2011), this scheme relates stomatal resistance $r_{s, i}$ of sunlit and shaded leaves $i$ to the photosynthesis rates $\left(A_{i}\right)$ per unit LAI of sunlit and shaded leaves $i$ separately:

$$
\frac{1}{r_{s, i}}=m \frac{A_{i}}{C_{\text {air }}} \frac{e_{\text {air }}}{e_{\text {sat }}(T V)} P_{\text {air }}+g_{\text {min }}
$$


where $C_{\text {air }}$ is $\mathrm{CO}_{2}$ concentration at the leaf surface. For our study period this was set at $400 \mathrm{ppmv}$ according to the median value of Atmospheric Carbon and Transport (ACT)-America B-200 aircraft near-surface (i.e., $>900 \mathrm{hPa}$ ) $\mathrm{CO}_{2}$ observations, which is close to the global monthly-mean $\mathrm{CO}_{2}$ concentrations in August 2016 (https://gml.noaa.gov/webdata/ccgg/trends/co2/co2_mm_gl.txt, lass access: 8 November 2021); TV, $P_{\text {air }}, e_{\text {air }}$, and $e_{\text {sat }}(T V)$ are canopy temperature, surface air pressure, vapor pressure at the leaf surface, and saturation vapor pressure inside leaf, respectively; $g_{\min }$ and $m$ are land cover dependent empirical parameters. $A_{i}$ is determined by equations (3)-(6):

$$
\begin{aligned}
& A_{i}=I_{g s} \min \left(A_{c}, A_{L, i}, A_{s}\right) \\
& A_{c}=\frac{\left(c_{i}-c_{c p}\right) V_{\max }}{c_{i}+K_{c}\left(1+\frac{o_{i}}{K_{O}}\right)} \\
& A_{L, i}=\frac{\left(c_{i}-c_{c p}\right) 4.6 \alpha P A R_{i}}{c_{i}+2 c_{c p}} \\
& A_{s}=0.5 V_{\text {max }}
\end{aligned}
$$

where $I_{g s}$ is a TV-dependent growing season index, $A_{C}, A_{L, i}$, and $A_{S}$ are carboxylase-limited, light-limited, and export-limited photosynthesis rates per unit LAI, respectively; $c_{i}$ and $o_{i}$ are $\mathrm{CO}_{2}$ concentrations inside leaf cavity which is about 0.7 times of the atmospheric $\mathrm{CO}_{2}$ concentration and atmospheric $\mathrm{O}_{2}$ concentration, respectively. $P A R$ represents the photosynthetically active radiation per unit LAI. $c_{c p}$ is the $\mathrm{CO}_{2}$ compensation point and it equals to $0.5 \frac{K_{c}}{K_{o}} 0.21 o_{i}$, where $K_{c}$ and $K_{o}$ are the Michaelis-Menton constants for $\mathrm{CO}_{2}$ and $\mathrm{O}_{2}$, respectively, varying with TV; $\alpha$ is the quantum efficiency. $V_{\max }$ represents the maximum rate of carboxylation, expressed as:

$$
V_{\max }=V_{\max 25} \alpha_{\text {vmax }}^{\frac{T V-25}{10}} f(N) f(T V) \beta
$$

where $V_{\max }$ is maximum carboxylation rate at $25^{\circ} \mathrm{C} ; f(T V)$ is a function that mimics thermal breakdown of metabolic processes; $f(N)$ is a foliage nitrogen factor; and $\beta$ is the SM factor controlling $\mathrm{R}_{\mathrm{s}}$, which presents strong dependencies on soil type and hydrological regime. In this study model results based on the Noah and the Community Land Model (CLM) types of $\beta$ schemes are compared (Table 1), the latter of which is known to often result in sharper and narrower ranges of variation with SM than the former does.

Other Noah-MP configurations include: the three-layer snowpack physics and the CLASS snow surface albedo; the Jordan scheme for partitioning precipitation into rainfall and snowfall; the Niu-Yang-2006 frozen soil permeability and supercooled liquid water option; the Simple Groundwater Model runoff scheme; and the Monin-Obukhov $\mathrm{C}_{\mathrm{H}}$ scheme, which, unlike

190 Noah's default Chen97 scheme, accounts for the zero-displacement height. Being affected by stability correction and additional effects of planetary boundary layer height on friction velocity, it is likely that the Monin-Obukhov scheme can result in either weaker or greater $\mathrm{C}_{\mathrm{H}}$ (i.e., less or more efficient ventilation of the land surface) than the Chen97 scheme during the daytime in summer (Niu et al., 2011; Yang et al., 2011). 
Irrigation process was included in all Noah-MP based simulations in this study. The benefit of including irrigation relies on the choice and parameterization of the irrigation scheme, as well as the LSM model's inputs (Lawston et al., 2015). Sprinkler scheme was chosen as it was reported as the prevalent irrigation method in 2015 across the US and many of the states within our model domain (Dieter et al., 2018). Irrigation was triggered over irrigated land in growing season within local morning times $(6-10 \mathrm{am})$ when rootzone SM drops below $50 \%$ of the soil field capacity. The irrigated land was determined by the model's LULC input and irrigation intensity information in Salmon et al. (2015), and the rootzone area was derived from the maximum root depth, which varies by crop type and GVF.

\subsection{Wesely and dynamic $\mathrm{O}_{3}$ dry deposition schemes}

Dry deposition velocity $V_{d}$ is estimated based on the resistance analogy approach:

$V_{d}=\frac{1}{\left[R_{a}+R_{b}+R_{c}\right]}$

$205 R_{a}$ and $R_{b}$ are aerodynamic resistance and quasi-laminar sublayer resistance, respectively, sensitive to surface properties such as surface roughness. Over the land, surface resistance $R_{c}$, the major component of $V_{d}$, is classified into stomatalmesophyll resistance $\left(R_{s}-R_{m}\right)$, cuticular resistance $\left(R_{l u}\right)$, in-canopy resistance $\left(R_{d c}\right.$ and $\left.R_{c l}\right)$, and ground resistance $\left(R_{a c}\right.$ and $\left.R_{g s}\right)$ :

$R_{c}=\frac{1}{\left[\frac{1}{R_{S}+R_{m}}+\frac{1}{R_{l u}}+\frac{1}{R_{d c}+R_{c l}}+\frac{1}{R_{a c}+R_{g s}}\right]}$

210 where $R_{d c}$ is resistance for gas-phase transfer affected by buoyant convection in the canopy when sunlight heats the (near)surface, $R_{c l}$ is resistance for leaves, twigs, bark, and others in the lower canopy, $R_{a c}$ is resistance for transfer that depends mostly on canopy structure, and $R_{g s}$ is resistance for soil, leaf litter, snow, and others at the ground surface.

Two deposition schemes, namely the Wesely and a dynamic scheme, were applied in this study, in which $R_{s}$ and $R_{l u}$ are

treated differently. In the Wesely scheme, $R_{s}$ and $R_{l u}$ are calculated based on (10) and (11):

$R_{s}=\left\{\begin{aligned} r_{s}\left\{1+\left[\frac{200}{G+0.1}\right]^{2}\right\}\left\{\frac{400}{T_{S}\left(40-T_{S}\right)}\right\} \frac{D_{\mathrm{H}_{2} \mathrm{O}}}{D_{x}}, \quad 0{ }^{\circ} \mathrm{C} \leq T_{s} \leq 40{ }^{\circ} \mathrm{C} \\ \sim 9999,>40{ }^{\circ} \mathrm{C} \text { or } T_{S}<0{ }^{\circ} \mathrm{C}\end{aligned}\right.$

$R_{l u}=\frac{r_{l u}}{10^{-5} H+f_{0}}+1000 e^{-T_{s}-4}$, for dry surfaces according to humidity and precipitation fields

Where $r_{s}$ and $r_{l u}$ are LULC- and season-dependent constants subject to uncertainty; $G$ and $T_{s}$ are radiation and surface temperature, respectively, whose definitions are different than those of $P A R$ and $T V$ in equations (2)-(7); $D_{\mathrm{H}_{2} \mathrm{O}}$ and $D_{x}$ are molecular diffusivities for water vapor and trace gas $x$ (e.g., $\mathrm{O}_{3}$ ), respectively; $H$, which is sensitive to surface temperature, represents the Henry's law constant for the focused trace gas; and $f_{0}$ is a reactivity factor for oxidation. The Wesely-scheme related results new from this study and Huang et al. (2021) are compared (Table 1). 
As expressed in equations (12), in the dynamic scheme, $R_{S}$ used in dry deposition modeling was taken from $R_{S}$ calculated

from Noah-MP's dynamic vegetation model, and thus considers the physiological process of leaf responses to photosynthesis rate, humidity and $\mathrm{CO}_{2}$ concentrations. The direct effects of $\mathrm{SM}$, as reflected in the $\beta$ formula, as well as other environmental variables, are included in this method, and this work quantifies the impact of the $\beta$ factor configurations in Noah-MP (Table 1) on the dynamic-scheme-related results.

$R_{S}=\left(\frac{r_{s, \text { sunlit }} L_{\text {sunlit }}+r_{S, \text { shaded }} L_{\text {shaded }}}{L A I}\right) \frac{D_{\mathrm{H}_{2} \mathrm{O}}}{D_{x}}$

where $r_{s, \text { sunlit }}$ and $r_{s, \text { shaded }}$ are computed based on equations (2)-(7), $L_{\text {sunlit }}$ and $L_{\text {shaded }}$ are proportional to the sunlit and shaded fractions of canopy, respectively, calculated based on the modified two-stream radiation transfer scheme.

In the dynamic scheme, $R_{l u}$ for dry surfaces is modified from the Wesely formula by considering its LAI dependency:

$R_{l u}=\frac{r_{l u}}{L A I \times\left(10^{-5} H+f_{0}\right)}+1000 e^{-T_{S}-4}$

In both the Wesely and the dynamic schemes, $R_{d c}$ is sensitive to surface radiation, and $R_{m}$ is expressed as:

$R_{m}=\frac{1}{\frac{H}{3000}+100 f_{0}}$

Similar to the $R_{l u}$ calculations in equations (11) and (13), to approximate an effect that coldness sometimes reduces the uptake, $1000 e^{-T_{s}-4}$ is added to LULC- and season-dependent constants to derive $R_{g s}$ and $R_{c l}$. It is worth mentioning that the direct effects of water stress on mesophyll resistance have been recognized (e.g., Egea et al., 2011). Yet, in neither scheme we applied, such effects have been incorporated into the $R_{m}$ formula as a part of the $V_{d}$ calculation.

\subsection{Model evaluation, analysis, and $\mathrm{O}_{3}$ impact assessments}

For the cases listed in Table 1, we quantify the impacts of SM DA on the modeled SM, vegetation dynamics, surface fluxes (i.e., gross primary productivity, GPP, which is integrated by LAI from $A$ in equations (2)-(3), energy fluxes and their partitioning in the format of evaporative fraction, dry deposition flux and individual $\mathrm{V}_{\mathrm{d}}$ terms for $\mathrm{O}_{3}$ particularly $R_{S}$ and $R_{l u}$ related), meteorological and surface $\mathrm{O}_{3}$ fields during the 16-28 August 2016 period. The SM DA impacts on most of these model fields are expressed as daily or/and daytime ( 13:00-24:00 UTC) averaged absolute or relative changes referring to the results from the no-DA cases. For $\mathrm{O}_{3}$ dry deposition fluxes, we also conducted linear regression analyses to determine the relationships between the relative flux changes versus the relative changes in column-averaged initial SM due to the DA. Results of $\mathrm{O}_{3}$ dry deposition fluxes and the regression analyses (i.e., slopes, correlation coefficient $r$ values, and $p$ values) are summarized by grouped LULC types defined in Figure 1a.

A variety of data products were utilized in this study to assess the model performance in no-DA and DA cases. Many of these evaluation datasets have been applied and introduced in detail in Huang et al. (2021), which are: 1) National Centers for Environmental Prediction Global Surface Observational Weather Data as well as weather data collected onboard the NASA B-200 aircraft during the ACT-America campaign; 2) hourly $\mathrm{O}_{3}$ measurements at the US Environmental Protection 
Agency Clean Air Status and Trends Network (CASTNET) and Air Quality System (AQS) sites; and 3) the $0.5^{\circ} \times 0.5^{\circ}$, daily FLUXCOM latent and sensible heat fluxes. New evaluation datasets used in this work include: 1) the $9 \mathrm{~km}$ VOD retrievals from the enhanced SMAP product, which indicates the attenuation of microwave signals by vegetation, proportional to above-ground canopy biomass, and was used together with a 10-day average Copernicus Global Land Service GVF product to derive GVF for the focused 13-day period; 2) the daily GPP estimates from the $9 \mathrm{~km}$ SMAP level 4 carbon (L4C) product version 6, developed based on the SMAP L4 surface $(0-5 \mathrm{~cm})$ and rootzone $(0-100 \mathrm{~cm}) \mathrm{SM}$ together with satellite LULC and vegetation datasets, which was supplemented by two independent GPP proxies (Whelan et al., 2020) of satellite-derived solar-induced chlorophyll fluorescence (SIF) data (Yu et al., 2019) and the Portable Flask Package (Sweeney et al., 2015) carbonyl sulfide (OCS) measurements collected onboard the B-200 and C-130 aircraft during the ACT-America campaign, and other airborne trace gas (e.g., benzene) measurements during this campaign were analyzed together with the OCS data to help distinguish the influences of combustion sources from plant $\mathrm{CO}_{2}$ uptake on the observed OCS distributions; and 3) $\mathrm{V}_{d}$ data from selected CASTNET sites, estimated using a multilayer model (MLM, not supported by CASTNET as of 2017) version 3.0 which has known limitations and biases against eddy covariance flux measurements as well as $V_{d}$ estimated using other methods (e.g., Finkelstein et al., 2000; Saylor et al., 2014; Wu et al., 2018). The known limitations of MLM and how they may affect our model comparisons with the CASTNET $\mathrm{V}_{d}$ data are discussed. Our $\mathrm{O}_{3}$ dry deposition results are also compared with eddy covariance measurements reported in independent works for similar climate or/and LULC types during other time periods.

This study also evaluates how the SM DA affected the assessments of surface $\mathrm{O}_{3}$ impacts on human and ecosystem health. Specifically: 1) MDA8 $\mathrm{O}_{3}$ fields over unban and nonurban regions were investigated linked to their respective population ranges; and 2) LULC-specific $\mathrm{O}_{3}$ stomatal uptake $F_{S}$ in the format of Phytotoxic Ozone Dose above the critical level of $y$ $\mathrm{nmol} \mathrm{m} \mathrm{s}^{-2}\left(\mathrm{POD}_{\mathrm{y}}\right)$, as well as crop-specific AOT40, were evaluated based on equations (15) and (16).

POD $_{y}\left(\mathrm{mmol} \mathrm{m}^{-2}\right)=\sum\left[\left(F_{S}-y\right) \times \frac{3600}{10^{6}}\right]$, for hourly daytime stomatal uptake $F_{S}>y \mathrm{nmol} \mathrm{m}^{-2} \mathrm{~s}^{-1}$

AOT40 $($ ppmh $)=\sum[(C-0.04)]$ for hourly daytime $\mathrm{O}_{3}$ concentration $C>0.04 \mathrm{ppmv}$

The calculated $\mathrm{POD}_{\mathrm{y}}$ and AOT40 were used to estimate the Relative Biomass Loss (RBL) or Relative Yield Loss (RYL) for 280 several types of vegetation or crops based on dose-response functions reported in literature (Table 2, Convention on LongRange Transboundary Air Pollution, CLRTAP, 2017; Mills et al., 2007, 2018a). Our 13-day WRF-Chem model results were linearly-extrapolated to $\sim$ three months to derive the $\mathrm{POD}_{\mathrm{y}}$ and $\mathrm{AOT} 40$ fields. We focus on qualitatively interpreting the results and discussing their implications. The outcome from this analysis is also compared with the findings from several independent $\mathrm{O}_{3}$ impact assessment studies for different time periods. 


\section{Results and discussions}

\subsection{Modeled SM and vegetation fields}

Figure 2 compares the horizontal and vertical gradients of the modeled initial SM conditions from the Noah_D and CLM_D cases defined in Table 1. At the surface layer $(0-10 \mathrm{~cm}$ belowground), both cases produced SM horizontal gradients that resemble the Noah-based results presented in Huang et al. (2021). They are moderately correlated with the column-averaged SM fields ( $r=0.875$ and 0.871 , respectively), and the mean differences in column-averaged and surface SM from the Noah_D and CLM_D cases are 0.003 and $-0.006 \mathrm{~m}^{3} \mathrm{~m}^{-3}$, respectively. Kumar et al. (2009) have found that, compared to other LSMs such as the Catchment (based on which the SMAP L4 datasets are produced), the 4-soil-layer Noah and 10-soil-layer CLM LSMs display successively weaker surface-subsurface coupling strengths, and the weakest coupling strength of CLM was primarily attributed to its significantly larger number of soil layers. The slightly weaker surface-subsurface correlations in the CLM_D case than in the Noah_D from this work, both are based on a 4-soil-layer Noah-MP modeling system, indicate the minor role of the LSM physics, in particular the $\beta$ factor scheme, in controling the vertical coupling strength of SM conditions.

300 The modeled SM fields from the Noah_D and CLM_D differ on grid scale, particularly in the subsurface zones (Figure 2ab). For example, in sand-dominant regions that were experiencing drought conditions during this period (e.g., Florida and the Texas-Oklahoma border regions, where simulated SM is mostly under $0.2 \mathrm{~m}^{3} \mathrm{~m}^{-3}$ ), column-averaged SM values from the CLM_D case are notably smaller than those from the Noah_D case. These results contrast with those reported by Niu et al. (2011), in which cases Noah-MP with the CLM-type $\beta$ factor consumed less soil water, resulting in smaller SM variability than did the Noah-type $\beta$ factor during drought periods. In their cases focusing on loam and clay soil that have higher wilting points when the CLM-type $\beta$ factor scheme was applied, plant transpiration ceased to save soil water under drought conditions. Our results can be explained by the steeper CLM-type $\beta$-SM curve than the Noah-type $\beta$-SM curve for low SM, sand-dominant areas, as illustrated in Figure 3a of Niu et al. (2011). For such conditions, Noah-MP with the CLM-type $\beta$ factor produces stronger evapotranspiration (ET) and consumes more soil water, resulting in drier soil. For wet regions where SM values exceed $0.4 \mathrm{~m}^{3} \mathrm{~m}^{-3}$, such as Louisiana and Arkansas, the CLM- and Noah-type $\beta$ values are close to 1.0 and insensitive to soil type and SM variations; therefore, SM and ET produced from the Noah_D and CLM_D cases do not diverge. These findings corroborate the conclusions by Yang et al. (2011) that the degree of the $\beta$ impacts on the SM-ET relationship should depend on the soil type and hydrological regime, and they are important for understanding the vegetation and surface flux results to be presented in the later parts of this paper.

Referring to the SMAP SM data, in general, surface SM produced by the no-DA modeling systems show wet biases in nonforested regions and dry biases over the forests for the study period. These SMAP-model discrepancies were successfully reduced by the DA for all vegetated LULC groups (Figure S1), leading to overall slightly drier soil in DA-enabled 
simulations. For both the Noah_D and CLM_D cases, the DA adjusted the modeled SM fields across the entire soil columns, demonstrating that observational information at the surface was propagated into deep soil layers. The SM responses to the DA as a function of soil layer from the Noah_D and CLM_D cases are roughly similar but different at small spatial scales, which reflect the controls of the $\beta$ factor scheme on the surface-subsurface coupling strengths of the used modeling/DA system. With the SMAP DA enabled, the $r$ values between column-averaged and surface SM from the Noah_D and CLM_D cases increased to 0.902 and 0.897 , respectively.

The satellite-derived GVF fields (methods introduced in Figure S2 caption) transition from low-to-moderate $(<0.6)$ to high $(>0.8)$ values from the western (mostly shrub/grasslands) to the central and eastern parts (forests/croplands dominant) of the study region, and such spatial gradients are highly correlated with the SMAP VOD retrievals (Figure 3a;d). The Noah_D and CLM_D cases both moderately well reproduced these spatial patterns. Major differences between these cases are found in dry sandy regions, where, as discussed in previous paragraphs, more soil water was consumed for ET and plant growth in the CLM_D case and therefore higher GVF values are given. The DA adjusted the modeled GVF and SM fields toward similar directions, with the relative changes in GVF overall smaller. While the SM changes in the Noah_D and CLM_D cases are of close magnitudes, GVF responded more strongly in the CLM_D case except for sandy regions. Referring to the satellitederived GVF fields which are also subject to large uncertainty, the modeled vegetation fields are more effectively improved by the DA over sparsely vegetated regions such as the South-Central Plains. The DA also remarkably reduced the modelsatellite mismatches over some of the dense vegetation regions such as the southwestern Ohio. The likely degraded model performance over certain dense vegetation areas can be partially explained by weaknesses related to SM-vegetation growth feedbacks in the dynamic vegetation model parameterizations which need to be identified and addressed in future work. It is also suggested that jointly assimilating satellite SM and vegetation phenology products such as the VOD retrievals needs to be experimented which may maximize the positive DA impacts on multiple land variables and their atmospheric feedbacks.

\subsection{Modeled fluxes and weather conditions}

\subsubsection{Carbon/energy fluxes and weather conditions}

Figure 4 compares the spatial distributions of the period-mean WRF-Chem carbon and energy fluxes with SMAP L4C and FLUXCOM products which contain observation information, and Table 3 summarizes WRF-Chem and observation-derived

345 flux results by three LULC groups. The observation-derived products indicate the highest GPP and evaporative fraction (EF $=$ daily latent heat/(daily latent heat + daily sensible heat)) over croplands. Without the DA, the Noah-MP related cases outperformed the Noah related P1_W case on simulating EF, especially over shrub/grassland and cropland regions. This indicates that, from Noah to Noah-MP, the multiple updates in LSM physics related to $\mathrm{R}_{\mathrm{s}}$, irrigation and $\mathrm{C}_{\mathrm{H}}$, are beneficial. Larger GPP and EF values are found in CLM_D than in Noah_D, most of which match better with the SMAP L4C and 350 FLUXCOM data. The DA led to increased EF over shrub/grasslands in all model cases as well as over croplands in the 
Noah_D case, bringing the model results closer to the FLUXCOM data. The EF values were unfavorably reduced by the DA in the CLM_D and P1_W cases over croplands and in all model cases over forests, reflecting the challenges of satellite SM DA over regions with dense vegetation and/or affected by human activities, which have also been reported in previous studies. For the Noah_D and CLM_D cases, this may also be due to the possibly degraded vegetation performance discussed in Section 3.1. The modeled GPP in the CLM_D cases were lowered by the DA overall, which helped reduce the modelSMAP L4C discrepancies over forests and croplands. In the Noah_D case, GPP was improved by the DA over forests and (slightly) over shrub/grasslands. Based on the evaluation statistics, for this case, the CLM type of $\beta$ factor scheme is shown slightly superior to the Noah type. Note that the quality of the SMAP L4C and FLUXCOM products may also be strongly LULC dependent, e.g., it has been known that the uncertainty of SMAP L4C data is generally larger for highly productive plant functional types (Kimball et al., 2020). Such evaluation, therefore, has demonstrated the critical role of LULC type in understanding the model performance of carbon and energy fluxes and its responses to satellite SM DA.

Additional datasets were also utilized to help understand terrestrial carbon uptake, including satellite SIF and ACT-America aircraft OCS as well as its vertical gradients (Figure S3). Consistent with the SMAP L4C and WRF-Chem based results, the largest SIF values are shown over croplands, especially maize and soybean fields in Illinois and Indiana, 2-3 times as high as those over shrub/grasslands in the South-Central Plains. Free-tropospheric ( $>2 \mathrm{~km}$, above ground level, a.g.l.) OCS mixing ratios are mostly higher than those near the surface ( $\leq 2 \mathrm{~km}$, a.g.1.), except for locations that may be strongly influenced by oceanic and anthropogenic combustion sources according to independent studies (Lennartz et al., 2017; Zumkehr et al., 2018) and other chemical tracers (e.g., benzene) measured onboard. The maximum OCS mixing ratios are higher than 550 pptv, and the OCS drawdowns (i.e., free-tropospheric minus near-surface concentrations) far exceed 60 pptv around the Lower Mississippi cropland regions and the Texas-Oklahoma border where soil was wet and likely an OCS source (Bunk et al., 2017). These values are much larger than those observed in summer 2004 over the eastern US (Campbell et al., 2008), indicating possible higher OCS emissions and stronger terrestrial carbon uptake in summer 2016 than in summer 2004.

In general, the modeled EF fields as well as their directions of changes due to the DA resemble those of latent heat flux and relative humidity (RH), which are opposite to those of sensible heat and surface temperatures (Figures 5 and S4). The model overall well reproduced the observed spatiotemporal variability of $2 \mathrm{~m}$ air temperature (T2) and RH, as well as FLUXCOM latent and sensible heat fluxes. The diagnostic $2 \mathrm{~m}$ weather fields and their responses to the DA strongly correlate with the model results at its surface level. The Noah-MP related cases reacted more strongly to the DA than the Noah-related cases, with the responses in the CLM_D case larger than in the Noah_D case except for dry, sandy regions, which can be attributed to combined effects of the used $\mathrm{C}_{\mathrm{H}}$ and stomatal resistance schemes. It is important to note that diagnostic temperature and humidity variables are represented differently in Noah and Noah-MP and thus are not directly comparable. Specifically, in Noah, T2 is an explicit function of skin temperature, air density, specific heat of dry air at constant pressure, and $2 \mathrm{~m}$ surface exchange coefficient for heat, and $2 \mathrm{~m}$ specific humidity is a function of surface specific humidity, upward moisture flux at 
the surface, air density and $2 \mathrm{~m}$ surface exchange coefficient for moisture; whereas in Noah-MP, they are expressed as functions of temperatures and water vapor for vegetated land and bare soil being weighed by their respective fractions. We therefore focus on quantitatively evaluating and intercomparing prognostic model weather variables (i.e., the model-level air temperature and humidity) against ACT-America aircraft observations (Figure 6). For air temperature, at all altitudes and near the surface (i.e., $\geq 800 \mathrm{hPa}$ ), the CLM_D case responded most strongly to the DA, and the DA-enabled CLM_D case outperformed the Noah_D and P1_W cases. This performance is qualitatively consistent with the model's sensible heat performance referring to the FLUXCOM data. As for humidity, despite the most significant DA improvements in CLM_D, the Noah-MP related cases did not perform as well as the Noah related cases, which is also found in the model's latent heat performance in comparison with the FLUXCOM data. However, note that the model's humidity performance is more strongly related to that of $R_{s}$ and $V_{d}$ in the Noah-MP based cases via the direct impacts of humidity on $R_{s}$ calculations (equation 2). The solar radiation fields from all model cases, which play vital roles in controlling the land-atmosphere exchanges of water and trace gases, do not differ dramatically and their responses to the DA are negligible (e.g., Figure 5g1). This indicates that the DA impacts on the modeled surface fluxes resulted primarily from the changes in the modeled SM, humidity, surface/canopy temperatures, as well as vegetation fields.

\subsubsection{Ozone dry deposition velocities and fluxes}

400 Figure 7 presents the period-mean, daily-averaged $V_{d}$ and dry deposition flux $F_{t}$ (i.e., $V_{d}$ multiplied by concentration at the surface level, Wesely, 1989) for $\mathrm{O}_{3}$ from all model cases, along with their responses to the SMAP DA. The daytime averages of these fields have similar spatial gradients but of larger magnitudes (not shown in figures). Table 3 summarizes for three LULC groups the daily- and daytime-averaged results. The modeled stomatal-mesophyll and cuticular conductances, as well as their diurnal variability are indicated in Figure 8. All model cases produced lower $V_{d}$ and $F_{t}$ values over shrub/grasslands than over forests and croplands, qualitatively consistent with results from many existing model- and measurement-based studies. The results from Noah_W and P1_W, both of which are based on the same scheme (Wesely), are generally similar, with minor differences largely attributed to different surface temperature fields (Figures 5 and S4). The WRF-Chem modeled $V_{d}$ and $F_{t}$ fluxes were more strongly affected by the upgrade from the Wesely to the dynamic scheme: i.e., with the updated scheme, they show enhanced magnitudes, stronger spatial variability, as well as more intensive responses to the DA, especially over forests and croplands. These results can be mainly explained by the fact that the stomatal-mesophyll and cuticular resistances in the dynamic scheme are sensitive to more environmental and biophysical variables, accounting for both the direct and indirect (i.e., via influencing the weather fields and plants' physiology) effects of $S M$ on $V_{d}$. $V_{d}$ from the Noah_D and CLM_D cases, as well as its major term stomatal-mesophyll conductance, show strong correlations with the modeled GPP, latent heat, and EF fields which have been discussed in earlier sections. Comparing the cases that

415 implemented the CLM- and Noah-like $\beta$ schemes, $\mathrm{O}_{3}$-related fluxes resulting from the former configuration are of notably larger magnitude, spatial variability and absolute changes due to the DA. The SM impacts on the modeled $V_{d}$ and $F_{t}$ were further quantified using linear regression analyses between the relative changes in the modeled $\mathrm{O}_{3}$ fluxes due to the DA 
versus those in column-averaged SM initial conditions. All regression models yielded low $p$ values (i.e., $<<0.01$ ), suggesting good $\Delta \mathrm{V}_{\mathrm{d}} \sim \Delta \mathrm{SM}$ and $\Delta \mathrm{F}_{\mathrm{r}} \sim \Delta \mathrm{SM}$ relationships. The regression slopes are summarized in barplots (Figure 9) by three LULC groups for all model cases in Table 1. For all LULC groups, the slopes based on the two cases that implemented the dynamic scheme are 2-3 times larger than those from the two cases using the Wesely scheme, and the slopes differ most strongly among cases over forests and croplands. The low $r$ values associated with several regression models (denoted by red "L"s in Figure 9) reflect the stronger nonlinear relationships between the changes in the studied $\mathrm{O}_{3}$ fluxes and SM. These results emphasize the importance of better understanding and realistically representing in models the SM control on plants' stomatal behaviors which regulate the land-atmosphere exchanges of water, energy, and trace gases. The earlier evaluation of the period-mean GPP and ET across the domain have demonstrated some advantages of using the CLM-like $\beta$ scheme, and that the DA more effectively improved the model performance in sparsely vegetated shrub/grassland regions. These conclusions are likely also applicable to the modeled $\mathrm{O}_{3}$ dry deposition process, particularly its stomatal-mesophyll pathway.

In all no-DA and DA cases, the diurnal variability of $\mathrm{O}_{3}$-related surface fluxes shows clear LULC dependency. Over the shrub/grassland and forests/croplands regions, the daytime averaged $\mathrm{V}_{\mathrm{d}}$ values are $24-31 \%$ and $35-50 \%$ higher than the $24 \mathrm{~h}$ mean, respectively, while the daytime averaged $\mathrm{F}_{\mathrm{t}}$ results are $40-50 \%$ and $42-63 \%$ higher than the $24 \mathrm{~h}$ mean, respectively (Table 3). Such $V_{d}$ diurnal cycles are a result of the strongest diurnal variability in stomatal-mesophyll conductance (i.e., its daytime mean values are $\sim$ twice as high as the $24 \mathrm{~h}$ mean for all LULC types) being balanced out by weak diurnal variability associated with other $\mathrm{V}_{\mathrm{d}}$ terms. As the most diurnally variable $\mathrm{V}_{\mathrm{d}}$ component, stomatal-mesophyll conductance, on average, contribute less substantially to $\mathrm{V}_{\mathrm{d}}$ for shrub/grassland areas (24 h/daytime: up to $\sim 30 \% / 40 \%$ ) than for forests/croplands (24 $\mathrm{h}$ /daytime: up to $\sim 50 \% / 66 \%$ ), which helps explain the weaker diurnal variability in the modeled $\mathrm{V}_{\mathrm{d}}$ over shrub/grasslands. The stronger diurnal cycles in $\mathrm{F}_{t}$ than in $\mathrm{V}_{d}$ reflect the impacts of higher daytime $\mathrm{O}_{3}$ surface concentrations used in the $\mathrm{F}_{t}$ calculations. The DA did not dominantly intensify or dampen the diurnal cycles of these fluxes for any given grouped LULC type. Whether the DA improved the estimated diurnal cycles of fluxes for various LULC types remains to be evaluated, which can benefit from independent observation-constrained flux products of broad spatial coverage and subdaily variability.

A detailed analysis was then conducted at two forest CASTNET sites with different soil types and hydrological regimes. The modeled $V_{d}$ and $F_{t}$ from various cases are compared with the operational MLM-based calculations produced at a Florida site SUM156 and a Virginia site PED108 (Figure 10a-d; Table 5). The dominant soil types at these sites are sand and loam, and the column-averaged SM values from various model cases are approximately 0.15 and $0.20 \mathrm{~m}^{3} \mathrm{~m}^{-3}$, respectively. All datasets show that $V_{d}$ and $F_{t}$ sharply increase soon after sunrise, reaching their daily maxima in late morning or early afternoon. The slight declines in fluxes around midday based on some simulations can result from the water and heat stresses which cause stomata closures. The water stress starts to get relieved since the mid-afternoon at the SUM156 site under the influences of convective precipitation whereas persists throughout the afternoon at the PED108 site (Figure 10e-f), which helps shape the slightly different afternoon flux dynamics at these two locations. Without the DA, at both sites, the highest daytime fluxes 
were produced from the CLM_D case, followed by the Noah_D and Noah_W cases, which are 2-3 times as high as the MLM-estimated. The fluxes from all WRF-Chem cases during the nighttime are close, up to $>80 \%$ lower than their daytime maxima, but still dramatically higher than the MLM-based results which are nearly zero. Our nighttime $V_{d}$ results are close to flux observations at European forest sites during both dry and wet periods in the past decades (Lin et al., 2020). Wu et al. (2018) compared $\mathrm{V}_{\mathrm{d}}$ observations with model calculations based on the operational MLM, Wesely, and a dynamic scheme Noah-GEM, at a Canadian mixed forest site dominated by sand-like soil. Their diverse model results are qualitatively consistent with our findings at these two CASTNET sites. The remarkably lower $\mathrm{V}_{\mathrm{d}}$ values from the operational MLM calculations are attributed to its simplified approaches of calculating $\mathrm{R}_{\mathrm{a}}$ and $\mathrm{R}_{\mathrm{b}} \mathrm{using}$ wind speed and direction, the empirical approach of calculating $\mathrm{R}_{\mathrm{s}}$, and the lack of continuous, accurate model input data. Within the respective ranges of the modeled SM at these two sites, $\beta$ factors based on the CLM-type scheme are both larger than those based on the Noah-type $\beta$ scheme (referring to Niu et al., Figure 3), which helps explain the higher model fluxes from the CLM_D case than the Noah_D case without the DA. At the SUM156 site, despite the strongest SM decrease $\left(\sim 0.04 \mathrm{~m}^{3} \mathrm{~m}^{-3}\right)$ by the DA in case CLM_D, the modeled fluxes responded least significantly to the DA, in part due to the flattened CLM-type SM- $\beta$ curves in 465 contrast to the linear Noah-type SM- $\beta$ function for sand within the $0.12-0.16 \mathrm{~m}^{3} \mathrm{~m}^{-3} \mathrm{SM}$ range. At the PED108 site, the modeled SM values from all model cases were lowered by the DA by $\sim 0.02 \mathrm{~m}^{3} \mathrm{~m}^{-3}$. The stronger flux reactions to the DA from the CLM_D case than those from the Noah_D case can be partially explained by the steep CLM-type SM- $\beta$ curve versus the linear Noah-type SM- $\beta$ relationship for loam within the $0.18-0.22 \mathrm{~m}^{3} \mathrm{~m}^{-3} \mathrm{SM}$ range. Case studies at these two sites with the same type of LULC emphasize the importance of soil type and hydrological regimes for understanding SM controls on dry deposition, which was often omitted or underdiscussed in previous dry deposition studies.

\subsection{Policy-relevant $\mathrm{O}_{3}$ metrics and implications for $\mathrm{O}_{3}$ impact assessments}

\subsubsection{MDA8 and implications for $\mathrm{O}_{3}$ health impacts}

Figure 11 illustrates the impacts of the choice of dry deposition scheme and SM DA on WRF-Chem modeled surface MDA8 $\mathrm{O}_{3}$. During the study period, several warmer- and drier-than-normal Atlantic states experienced high MDA8 at times (i.e., $475 \geq 60 \mathrm{ppbv}$, which can negatively affect lung function, and at $\geq 70 \mathrm{ppbv}$, cause respiratory symptoms and other adverse effects, Fleming et al., 2018, and references therein). Numerous populated urban centers reside in these areas. The levels of MDA8 are shown to be much lower (i.e., $<40 \mathrm{ppbv}$ ) over the southern part of the domain, including several major urban/suburban regions such as the Texas Triangle, which was frequently influenced by passing cold fronts and tropical systems from the Gulf of Mexico.

All model cases reproduced these MDA8 spatial patterns moderately well. Referring to observations at AQS and CASTNET sites, their domain wide mean RMSEs all fall within 6-8.5 ppbv (Figure 11m). We first intercompare the MDA8 levels from all no-DA cases. Positive and negative differences between the results from Noah_W and P1_W, both of which implemented 
the Wesely scheme, are almost equally distributed across the domain, with the MDA8 from the former case associated with negligibly lower RMSEs (i.e., $<0.02 \mathrm{ppbv}$ on average) referring to AQS and CASTNET observations (Figure 111-m). The differences between these two cases are largely due to the impact of the chosen LSM on the model's meteorological fields, particularly temperatures, which affected the simulations of various $\mathrm{O}_{3}$-related processes including dry deposition. As Figure $11(\mathrm{j} ; \mathrm{k} ; \mathrm{m})$ show, replacing Wesely with the dynamic dry deposition scheme considerably lowered the calculated MDA8 levels in majority of the model grids, as well as their associated RMSEs (i.e., by $>0.5$ ppbv on average) relative to surface observations. These reductions in MDA8 are of comparable magnitudes with those due to updating anthropogenic emissions from the National Emission Inventory 2014 to 2016beta (Huang et al., 2021). Comparing the implementations of CLM- and Noah-types of $\beta$ schemes, the former led to stronger reductions in the modeled MDA8 fields and their associated uncertainty. These results reflect the impacts of the faster $\mathrm{O}_{3}$ removal via dry deposition in the dynamic scheme related cases, as well as the different model meteorology. Our findings are qualitatively consistent with the conclusions from several global-scale modeling experiments that compared the Wesely and dynamic schemes (e.g., Val Martin et al., 2014; Lin et al., 2019).

In all model cases, the DA reduced surface and subsurface SM in many of the grids, leading to enhanced MDA8 (Figure 11fi). The responses of the period-mean MDA 8 to the DA from the Noah_W and P1_W cases are mostly within \pm 4 ppbv. When the dynamic dry deposition scheme was applied, the modeled MDA8 responded several times more strongly to the DA (i.e., by up to $6 \mathrm{ppbv}$ and $8 \mathrm{ppbv}$ in the Noah_D and CLM_D cases, respectively), especially over nonurban regions where surface MDA8 on average are several ppbv lower than in urban grids. In urban grids where population densities are $\sim 25$ times higher than in nonurban grids (Figure 1c), the DA impacts on MDA8 reach 3-4 ppbv in places, under the controls of the local-toregional circulation patterns (Figure $12 \mathrm{a} ; \mathrm{e}$ ). As the no-DA cases are positively biased against surface observations in many places, corresponding to the DA-induced surface $\mathrm{O}_{3}$ changes, the overall model performance of MDA8 was not improved, or much degraded, by the DA. Over limited areas such as the South-Central Plains, the modeled MDA8 decreased due to the DA by up to $>2 \mathrm{ppbv}$, corresponding to improved performance. The no-DA and DA results based on different LSMs and dry deposition schemes confirm that drier soil conditions exacerbate $\mathrm{O}_{3}$ air pollution, which, together with heat stress, threatens human health. Such $\mathrm{O}_{3}-\mathrm{SM}$ relationships have also been demonstrated by Falk and Søvde Haslerud (2019) and Anav et al. (2018) using other chemical transport models and multiplicative dry deposition schemes. Our Noah_W and P1_W related 510 results indicate the influences of SM on air quality via its feedbacks to weather; and results from the Noah_D and CLM_D cases provide valuable information regarding both the indirect (i.e., via adjusting vegetation phenology and weather conditions) and direct SM effects on $\mathrm{O}_{3}$. The complex SM impacts on $\mathrm{O}_{3}$ dry deposition as well as surface $\mathrm{O}_{3}$ concentrations based on the coupled photosynthesis- $R_{s}$ calculations rely heavily on the application of water stress function ( $\beta$ scheme), soil properties and hydrological regime. The WRF-Chem results from this case indicate that, to more accurately simulate MDA8, 515 improving land DA must be combined with aggressive efforts to identify other sources of uncertainty in $\mathrm{O}_{3}$ modeling (e.g., emissions, chemistry, and extra-regional pollution contributions) and reduce their negative impacts on model performance. 


\subsubsection{Implications for $\mathrm{O}_{3}$ vegetation impact assessments using concentration- and flux-based metrics}

Both $\mathrm{O}_{3}$ flux- and concentration-based metrics have been applied to assess $\mathrm{O}_{3}$ impacts on vegetation as well as the associated economic loss. Estimating the plants' stomatal $\mathrm{O}_{3}$ uptake $\mathrm{F}_{\mathrm{s}}$ is the basis for constructing flux-based $\mathrm{O}_{3}$ impact assessments. Figure 13 illustrates the period-mean daytime $\mathrm{F}_{\mathrm{s}}$ fields based on all WRF-Chem no-DA cases as well as their responses to the SM DA. Box-and-whisker plots in Figure 12(b;f) summarize these results by three LULC groups. The averaged $F_{s}$ values for all three LULC groups exceed their respective critical levels (i.e., $1 \mathrm{nmol} \mathrm{m}{ }^{-2} \mathrm{~s}^{-1}$ for forest and grasslands; and $3 \mathrm{nmol} \mathrm{m}^{-2}$ $\mathrm{s}^{-1}$ for crops). As a major contributor to $\mathrm{O}_{3}$ dry deposition flux during the daytime, $\mathrm{F}_{\mathrm{s}}$ fields appear to be closely correlated in space and time with the surface humidity and flux fields (e.g., GPP, latent heat and EF, as well as $V_{d}$ ), which differ distinctly from the surface $\mathrm{O}_{3}$ concentration fields. For example, $F_{s}$ hotspots are shown over some low $\mathrm{O}_{3}$ concentration areas including the humid, Lower Mississippi River regions, and the lowest $\mathrm{F}_{\mathrm{s}}$ values occur in certain high $\mathrm{O}_{3}$ concentration regions strongly affected by urban pollution (e.g., Georgia) and pollution transport from upwind US states and/or the stratosphere (e.g., western Kansas and Oklahoma, as discussed in Huang et al., 2021). The changes in $\mathrm{F}_{\mathrm{s}}$ and surface $\mathrm{O}_{3}$ concentrations due to the DA show opposite directions, i.e., drier soil enhances surface $\mathrm{O}_{3}$ concentrations whereas slows down the plants' stomatal $\mathrm{O}_{3}$ uptake (Figures 11f-i and 13e-h). This comparison highlights how the choice of $\mathrm{O}_{3}$ metrics can affect the assessment of $\mathrm{O}_{3}$ vegetation impacts under the changing climate. As emphasized by Mills et al. (2018a) and Ronan et al. (2020), flux-based metrics have evident advantages over concentration-based metrics. To conduct reliable impact assessments using these flux-based metrics, accurate information on stomatal and non-stomatal fluxes as well as the various environmental and biophysical variables that they are sensitive to become increasingly important.

An assessment of $\mathrm{O}_{3}$ vegetation impacts was conducted based on the results from various model cases and different metrics, namely POD $_{\mathrm{y}}$ (where y is LULC-dependent critical level) and AOT40. For this demonstration, the 13-day model results were linearly extrapolated to $\sim$ three months. This also assumed similar DA adjustments to SM dynamics (driven by factors such as clouds/radiation, rainfall, and irrigation for cropland-dominant regions) at the time scale of $\sim$ three months. Based on the

known seasonal variability of surface $\mathrm{O}_{3}$ and $\mathrm{V}_{\mathrm{d}}$ in the study region, the linearly scaled $\mathrm{POD}_{\mathrm{y}}$ and $\mathrm{AOT} 40$ values may have been overall underestimated. We therefore focus on discussing the results qualitatively and highlighting their implications for $\mathrm{O}_{3}$ impact assessments using long-term records. Statistics of the derived $\mathrm{POD}_{\mathrm{y}}$ and AOT40 fields are summarized by $\mathrm{O}_{3}$ sensitive LULC and crop types in Figure 12(c-d;g-h), and Figure 14 presents the estimated AOT40 fields as well as their responses to the SM DA for cropland-dominant grids. The highs and lows in AOT40-related results are found over maize and wheat dominant fields, respectively. Among the three focused LULC types, the highest and lowest POD $_{\mathrm{y}}$ values are estimated for forests and grasslands, respectively. Largely driven by daytime peak $\mathrm{O}_{3}$ concentrations, the spatial variability and biases (referring to AQS and CASTNET observations) of the model-derived AOT40 fields, as well as their responses to

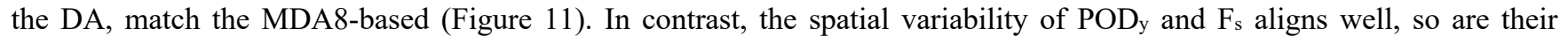


responses to the DA. Both $\mathrm{POD}_{\mathrm{y}}$ and AOT40 reacted several times more intensively in the cases that implemented the dynamic dry deposition scheme, especially the CLM_D case.

For selected LULC and crop types, the WRF-Chem derived $\mathrm{POD}_{\mathrm{y}}$ and AOT40 fields were used together with dose-response functions in literature to evaluate the RBL/RYL due to $\mathrm{O}_{3}$ exposure and uptake. As reported in Figure 12(c;g), with the SM DA enabled, the mean RBLs based on Noah_D and CLM_D derived POD y are 0.06-0.10, 0.02-0.03, and 0.04-0.05 for deciduous forest, grasslands and wheat, respectively, which are $>33 \%$ lower than the Noah_W and P1_W based RBL estimates. It is shown that, in response to the DA which lowered SM in many places, the Noah_W and P1_W based RBL estimates did not drop as strongly as the Noah_D and CLM_D based, and even increased for grasslands and wheat. For wheat, one of the most $\mathrm{O}_{3}$-sensitive crops, the estimated RYL values based on $\mathrm{POD}_{\mathrm{y}}$ and AOT40 approaches differ by up to a factor of 2-3, and the DA had contrasting effects on these estimates (Figure 12c-d;g-h). The POD $_{y}$ - and AOT40-based

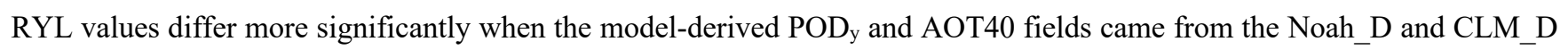
cases. Using the model-derived AOT40 and different AOT40 dose-response functions (Mills et al., 2007, 2018a, Table 2), the estimated RYLs and their changes due to the DA are nonnegligible (Figure 12d;h). Our estimated RBL/RYL results for various LULC and crop types mostly fall within the ranges reported in previous studies which applied model-derived $\mathrm{O}_{3}$ metrics and dose-response functions (e.g., Avnery et al., 2011; Mills et al., 2007, 2018a). Our results emphasize that the selected $\mathrm{O}_{3}$ impact assessment metrics for various LULC/crop types and their matching dose-response functions, as well as the model results used to derive the chosen $\mathrm{O}_{3}$ metrics which are sensitive to dry deposition schemes and SM, all introduce uncertainty to the estimated $\mathrm{O}_{3}$ impacts on vegetation. The widely-used dose-response functions are considered appropriate for studying North America and Europe, but they may not be applicable to other regions (Emberson et al., 2009). Therefore, updating and developing dose-response relationships for a larger number of vegetation types in different regions of the world are needed, which may require new experiments to be conducted. Yue and Unger (2014) and Lombardozzi et al. (2015) as well as follow-on investigations parameterized the $\mathrm{O}_{3}$ impacts on several types of vegetation using the relationships between cumulative $\mathrm{O}_{3}$ uptake and $\mathrm{O}_{3}$ damage factors for photosynthesis and conductance from empirical and experimental studies. Based on multi-decadal model simulations, they reported $<20 \%$ changes of biomass, GPP, and energy fluxes due to $\mathrm{O}_{3}$, which are roughly consistent with our RBL/RYL results in Figure 12. Such approaches that dynamically assess the impacts of $\mathrm{O}_{3}$ along with other factors (e.g., non- $\mathrm{O}_{3}$ pollutants and environmental stresses), as highlighted in Emberson et al. (2018), will be considered in future work.

We note that, revising the dry deposition scheme and constraining the modeled SM fields with observations would not only better be combined with adding $\mathrm{O}_{3}$ injury to vegetation but also multistress impacts on biogenic emissions. Considering $\mathrm{O}_{3}$ 580 injury to vegetation would affect more evidently longer-term climate simulations via feedbacks to biomass, surface fluxes, weather and weather-driven emissions. As for biogenic emissions, Figure S5 shows SM anomalies during the study period determined by our Noah-MP modeling system as well as drought stress activity factor $\gamma_{\mathrm{d}}$ estimated from $\beta$ of a multiyear, 
independent CLM simulation by Jiang et al. (2018). Based on these, we estimate that, depending on soil type, hydrological regime, as well as $\beta$ configurations, omitting the direct impacts of water stress on biogenic emissions, may have introduced larger uncertainty to biogenic emission and $\mathrm{O}_{3}$ modeling over several states experiencing drier-than-normal conditions, such as Tennessee, South Carolina, Alabama, and West Virginia. Quantitatively understanding the interplay between these processes and $\mathrm{O}_{3}$ pollution levels is recommended for more accurate air quality modeling and $\mathrm{O}_{3}$ impact assessments.

\section{Summary and suggestions on future directions}

This paper described a follow-up study of Huang et al. (2021). It presented how the choice of $\mathrm{O}_{3}$ dry deposition scheme affected our evaluation of SMAP SM DA impacts on coupled WRF-Chem modeling over the southeastern US in August 2016. In new Noah-MP LSM related simulations, two dry deposition schemes were implemented, namely the WRF-Chem default Wesely scheme and a dynamic scheme, in the latter of which the calculation of $\mathrm{V}_{\mathrm{d}}$ (particularly its stomatal and cuticular terms) were modified to be coupled with photosynthesis and vegetation phenology. We showed that dry deposition parameterizations significantly affected the modeled $\mathrm{O}_{3}$ dry deposition process, as well as its response to the DA. Comparing the no-DA cases, it was found that, when the dynamic scheme was applied, overall, the modeled $\mathrm{O}_{3}$ dry deposition velocities and fluxes were larger and surface $\mathrm{O}_{3}$ concentrations were lower. The modeled $\mathrm{O}_{3}$ fluxes responded 2-3 times more strongly to the SM changes due to the DA, which can be mainly explained by the fact that both the direct and indirect (i.e., via influencing weather and vegetation fields) effects of $\mathrm{SM}$ on $\mathrm{O}_{3}$ dry deposition modeling are considered in the dynamic scheme. Depending on soil type and hydrological regime, the selection of SM factor controlling $\mathrm{R}_{\mathrm{s}}$ (i.e., $\beta$ factor, a key variable representing the direct effects of SM on the modeled surface fluxes) scheme can strongly affect the quantitative results. The Wesely-scheme derived dry deposition results driven by meteorological fields from Noah-MP and Noah (from Huang et al., 2021) LSM based WRF-Chem simulations displayed much smaller differences than those due to updating the dry deposition parameterizations. While we note that accounting for physiological effects in dry deposition modeling can be beneficial, the Ball-Berry $\mathrm{R}_{\mathrm{s}}$ scheme applied in land surface and dry deposition modeling in this work needs to be compared with other semi-empirical $\mathrm{R}_{\mathrm{s}}$ schemes, for a better understanding of their respective strengths and weaknesses. Alternative schemes include the Medlyn scheme which has been integrated into the CLM version 5. Model intercomparison efforts such as the ongoing AQMEII4 activity (Galmarini et al., 2021) can also help determine areas for improvement in commonly-used dry deposition modeling approaches for studying 2016 and other years, over North America and other regions of the world.

610 By analyzing the model responses to the SM DA from these various cases, we conclude that, in coupled modeling systems that consider the direct and indirect influences of $\mathrm{SM}$ on $\mathrm{O}_{3}$ dry deposition, the accuracy of SM is particularly critical to dry deposition and $\mathrm{O}_{3}$ modeling, as well as the scientific analyses and impact assessments based on model simulations. The usefulness of SM DA for improving the modeled state and flux variables was evaluated by multiple observation(-derived) data products. Referring to in situ measurements, key meteorological variables relevant to $V_{d}$ calculations such as surface 
615 temperature and humidity are shown to be improved by the DA by up to $\sim 9 \%$. Referring to satellite(-derived) datasets which may be associated with high uncertainty, the model performance of vegetation phenology, GPP, as well as energy fluxes and their partitioning, showed mixed, LULC-dependent reactions to the DA. According to the evaluation statistics, for this case, the CLM type of $\beta$ factor scheme was slightly superior to the Noah type. The modeled carbon and energy fields as well as their DA-related changes, correlated strongly with the modeled $V_{d}$ fields, implying that the DA impacts on the accuracy of

$620 \mathrm{~V}_{\mathrm{d}}$ were also possibly complicated which is difficult to verify due to the lack of high-accuracy, independent $\mathrm{V}_{\mathrm{d}}$ evaluation datasets. Observation(-derived) $V_{d}$ datasets covering diverse LULC types nested in broad geographical regions and through more recent periods are in strong need. In places, the likely ineffectiveness of SM DA on vegetation and surface fluxes can not only be attributed to the quality of satellite SM retrievals and the used DA approach as discussed in previous Noah LSM based DA experiments, but also shortcomings in the Noah-MP LSM and its dynamic vegetation scheme regarding its 625 surface-subsurface coupling and representation of SM-vegetation growth feedbacks. Continued efforts on advancing land measurement/retrieval skills, identifying and addressing deficits in LSMs as well as practicing multivariate land DA are recommended in future work.

This study also demonstrated that, model-driven assessments of $\mathrm{O}_{3}$ impacts on human health and various types of vegetation can be significantly affected by the applied $\mathrm{O}_{3}$ dry deposition scheme, the implementation of land DA, the chosen $\mathrm{O}_{3}$ metrics and their matching exposure-response functions. Various model cases showed that, the DA impacts on MDA8 were more evident in nonurban areas where the mean MDA8 was $\sim 5$ ppbv lower and the averaged population density is $<1 / 25$ of those in urban areas. Using concentration- and flux-based metrics AOT40 and $\mathrm{POD}_{\mathrm{y}}$, the mean RYLs of maize, soybean, and wheat fell within ranges of $0.03-0.07,0.10-0.17$, and $0.04-0.14$, respectively. While the multiple no-DA and DA cases

635 helped us better understand the indirect or/and direct effects of $\mathrm{SM}$ on $\mathrm{O}_{3}$ dry deposition process, which has important implications for $\mathrm{O}_{3}$ impact assessments, it is recognized that, the DA often exacerbated the positive $\mathrm{O}_{3}$ biases in free-running systems which has been a common issue shared by numerous regional and global models for this study region/season. It is necessary to combine land DA with efforts to identify and reduce other sources of uncertainty in $\mathrm{O}_{3}$ modeling. These should include reasonably representing the impacts of $\mathrm{O}_{3}$ along with other factors on vegetation as well as the direct impacts of water stress on biogenic emissions of volatile organic compounds and nitrogen species.

\section{Code and data availability}

Dry deposition related updates to LIS/WRF-Chem since Huang et al. (2021) are undergoing reporting processes via NASA's New Technology Reporting System (https://invention.nasa.gov). Observations and observation-derived data sets used in this work but not in Huang et al. (2021) can be found at the following locations: https://doi.org/10.5067/L6C9EY1O8VIC 645 (Kimball et al., 2021), https://doi.org/10.7927/H49C6VHW (NASA Socioeconomic Data and Applications Center, 2018), https://www-air.larc.nasa.gov/cgi-bin/ArcView/actamerica.2016 (NASA, 2020, last access: 8 November 2021), 
https://java.epa.gov/castnet/clearsession.do (US Environmental Protection Agency, 2019, last access: 8 November 2021), and https://doi.org/10.3334/ORNLDAAC/1696 (Yu et al., 2019).

\section{Author contributions}

$650 \mathrm{MH}$ led the design and execution of the study as well as the paper writing, benefitting from discussions with JHC, GRC, KWB, and SVK, with the feedback from the Atmos. Chem. Phys. Editorial Board and reviewers for Huang et al. (2021) also accounted for. CS contributed to data collection during the ACT-America campaign. All authors helped finalize the paper.

\section{Competing interests}

The authors declare that they have no conflict of interest.

\section{Acknowledgements}

We acknowledge NASA SUSMAP sponsorship, as well as ACT-America Science Team and NASA's high-end computing systems and services at Ames and Goddard. We thank Jiang et al. (2018) for developing the $\gamma_{\mathrm{d}}$ dataset shown in Figure S5. We also greatly appreciate active and relevant discussions with multiple colleagues from the Air Quality Model Evaluation International Initiative 4 and the Tropospheric Ozone Assessment Report II communities during and after recent conferences

660 and workshops, particularly: C. Hogrefe, J. Pleim, P. Makar, L. Emberson, B. Sinha, D. Lombardozzi, O. Clifton, L. Emmons, T. Emmerichs, and D. Taraborrelli.

\section{References}

Anav, A., Proietti, C., Menut, L., Carnicelli, S., De Marco, A., and Paoletti, E.: Sensitivity of stomatal conductance to soil moisture: implications for tropospheric ozone, Atmos. Chem. Phys., 18, 5747-5763, https://doi.org/10.5194/acp-18-5747$6652018,2018$.

Avnery, S., Mauzerall, D. L., Liu, J., and Horowitz, L. W.: Global Crop Yield Reductions due to Surface Ozone Exposure: 1. Year 2000 Crop Production Losses and Economic Damage, Atmos. Environ., 45, 2284-2296, https://doi.org/10.1016/j.atmosenv.2010.11.045, 2011.

Baillie, A. L. and Fleming, A. J.: The developmental relationship between stomata and mesophyll airspace, New Phytol., 225, 1120-1126, https://doi.org/10.1111/nph.16341, 2019. 
Ball, J. T., Woodrow, I. E., and Berry, J. A. (1987), A model predicting stomatal conductance and its contribution to the control of photosynthesis under different environmental conditions, Process in Photosynthesis Research, 1, edited by J. Biggins, 221-234, Martinus Nijhoff, Dordrecht, the Netherlands.

Bunk, R., Behrendt, T., Yi, Z., Andreae, M. O., and Kesselmeier, J. (2017), Exchange of carbonyl sulfide (OCS) between soils and atmosphere under various $\mathrm{CO}_{2}$ concentrations, J. Geophys. Res. Biogeosci., 122, 1343-1358, https://doi.org/10.1002/2016JG003678.

Campbell, J. E., Carmichael, G. R., Chai, T., Mena-Carrasco, M., Tang, Y., Blake, D. R., Blake, N. J., Vay, S. A., Collatz, G. J., Baker, I., Berry, J. A., Montzka, S. A., Sweeney, C., Schnoor, J. L., and Stanier, C. O.: Photosynthetic control of atmospheric carbonyl sulfide during the growing season, Science, 322, 1085-1088, https://doi.org/10.1126/science.1164015, 2008.

Clifton, O. E., Paulot, F., Fiore, A. M., Horowitz, L. W., Correa, G., Baublitz, C. B., Fares, S., Goded, I., Goldstein, A. H., Gruening, C., Hogg, A. J., Loubet, B., Mammarella, I., Munger, J. W., Neil, L., Stella, P., Uddling, J., Vesala, T., and Weng, E.: Influence of dynamic ozone dry deposition on ozone pollution, J. Geophys. Res.-Atmos., 125, e2020JD032398, 690 https://doi.org/10.1029/2020JD032398, 2020.

Convention on Long-Range Transboundary Air Pollution (CLRTAP): Mapping Critical Levels for Vegetation, Chapter 3 of Manual for modelling and mapping critical loads and levels, available at: https://www.umweltbundesamt.de/en/manual-formodelling-mapping-critical-loads-levels (last access: 10 December 2021), 2017.

Dieter, C. A., Maupin, M. A., Caldwell, R. R., Harris, M. A., Ivahnenko, T. I., Lovelace, J. K., Barber, N. L., and Linsey, K. S., Estimated use of water in the United States in 2015: U. S. Geological Survey Circular 1441, 65, https://doi.org/10.3133/cir1441, 2018.

Ducker, J. A., Holmes, C. D., Keenan, T. F., Fares, S., Goldstein, A. H., Mammarella, I., Munger, J. W., and Schnell, J.: Synthetic ozone deposition and stomatal uptake at flux tower sites, Biogeosciences, 15, 5395-5413, https://doi.org/10.5194/bg-15-5395-2018, 2018.

Egea, G., Verhoef, A., and Vidale, P. L.: Towards an improved and more flexible representation of water stress in coupled photosynthesis-stomatal conductance models, Agric. For. Meteorol., 151, 1370-1384. https://doi.org/10.1016/j.agrformet.2011.05.019, 2011. 
Emberson, L. D., Büker, P., Ashmore, M. R., Mills, G., Jackson, L., Agrawal, M., Atikuzzaman, M. D., Cinderby, S., Engardt, M., Jamir, C., Kobayashi, K., Oanh, N. T. K., Quadir, Q. F., and Wahid, A.: A comparison of North American and Asian exposure-response data for ozone effects on yield, Environ. Pollut., 43, 1945-1953, https://doi.org/10.1016/j.atmosenv.2009.01.005, 2009.

Emberson, L. D., Pleijel, H., Ainsworth, E. A., van den Berg, M., Ren, W., Osborne, S., Mills, G., Pandey, D., Dentener, F., Büker, P., Ewert, F., Koeble, R. and Van Dingenen, R.: Ozone effects on crops and consideration in crop models, Eur. J. Agron., 100, 19-34, https://doi.org/10.1016/j.eja.2018.06.002, 2018.

Emmerichs, T., Kerkweg, A., Ouwersloot, H., Fares, S., Mammarella, I., and Taraborrelli, D.: A revised dry deposition scheme for land-atmosphere exchange of trace gases in ECHAM/MESSy v2.54, Geosci. Model Dev., 14, 495-519, https://doi.org/10.5194/gmd-14-495-2021, 2021.

Falk, S. and Søvde Haslerud, A.: Update and evaluation of the ozone dry deposition in Oslo CTM3 v1.0, Geosci. Model Dev., 12, 4705-4728, https://doi.org/10.5194/gmd-12-4705-2019, 2019.

Finkelstein, P. L., Ellestad, T. G., Clarke, J. F., Meyers, T. P., Schwede, D. B., Hebert, E. O., and Neal, J. A.: Ozone and sulfur dioxide dry deposition to forests: Observations and model evaluation, J. Geophys. Res., 105, 15365-15377, doi:10.1029/2000JD900185, 2000.

Fleming, Z. L., Doherty, R. M., von Schneidemesser, E., Malley, C. S., Cooper, O. R., Pinto, J. P., Colette, A., Xu, X., Simpson, D., Schultz, M. G., Lefohn, A. S., Hamad, S., Moolla, R., Solberg, S., and Feng, Z.: Tropospheric Ozone Assessment Report: Present-day ozone distribution and trends relevant to human health, Elem. Sci. Anth., 6, 12, https://doi.org/10.1525/elementa.273, 2018.

Fredericksen, T. S., Skelly, J. M., Steiner, K. C., Kolb, T. E., Kouterick, K. B.: Size-mediated foliar response to ozone in black cherry trees, Environ. Pollut., 91, 53-63, https://doi.org/10.1016/0269-7491(95)00032-m, 1996.

Galmarini, S., Makar, P., Clifton, O. E., Hogrefe, C., Bash, J. O., Bellasio, R., Bianconi, R., Bieser, J., Butler, T., Ducker, J., Flemming, J., Hodzic, A., Holmes, C. D., Kioutsioukis, I., Kranenburg, R., Lupascu, A., Perez-Camanyo, J. L., Pleim, J., Ryu, Y.-H., San Jose, R., Schwede, D., Silva, S., and Wolke, R.: Technical note: AQMEII4 Activity 1: evaluation of wet and dry deposition schemes as an integral part of regional-scale air quality models, Atmos. Chem. Phys., 21, 15663-15697, https://doi.org/10.5194/acp-21-15663-2021, 2021. 
Griffiths, P. T., Murray, L. T., Zeng, G., Shin, Y. M., Abraham, N. L., Archibald, A. T., Deushi, M., Emmons, L. K., Galbally, I. E., Hassler, B., Horowitz, L. W., Keeble, J., Liu, J., Moeini, O., Naik, V., O'Connor, F. M., Oshima, N., Tarasick, D., Tilmes, S., Turnock, S. T., Wild, O., Young, P. J., and Zanis, P.: Tropospheric ozone in CMIP6 simulations, Atmos. Chem. Phys., 21, 4187-4218, https://doi.org/10.5194/acp-21-4187-2021, 2021.

Hardacre, C., Wild, O., and Emberson, L.: An evaluation of ozone dry deposition in global scale chemistry climate models, Atmos. Chem. Phys., 15, 6419-6436, https://doi.org/10.5194/acp-15-6419-2015, 2015.

Hemispheric Transport of Air Pollution: Impacts on Health, Ecosystems, and Climate, Chapter 5 of 2010 Final Assessment report, Part A: Ozone and particulate matter, available at: http://htapold.kaskada.tk/publications/2010_report/2010_Final_Report/HTAP 2010 Part A 110407.pdf (last access: 16 November 2021), 2010.

755 Hollaway, M. J., Arnold, S. R., Challinor, A. J., and Emberson, L. D.: Intercontinental trans-boundary contributions to ozone-induced crop yield losses in the Northern Hemisphere, Biogeosciences, 9, 271-292, https://doi.org/10.5194/bg-9-2712012, 2012.

Huang, M., Carmichael, G. R., Chai, T., Pierce, R. B., Oltmans, S. J., Jaffe, D. A., Bowman, K. W., Kaduwela, A., Cai, C., 760 Spak, S. N., Weinheimer, A. J., Huey, L. G., and Diskin, G. S.: Impacts of transported background pollutants on summertime western US air quality: model evaluation, sensitivity analysis and data assimilation, Atmos. Chem. Phys., 13, 359-391, https://doi.org/10.5194/acp-13-359-2013, 2013.

Huang, M., Crawford, J. H., DiGangi, J. P., Carmichael, G. R., Bowman, K. W., Kumar, S. V., and Zhan, X.: Satellite soil moisture data assimilation impacts on modeling weather variables and ozone in the southeastern US - Part 1: An overview, Atmos. Chem. Phys., 21, 11013-11040, https://doi.org/10.5194/acp-21-11013-2021, 2021.

Intergovernmental Panel on Climate Change: the Sixth Assessment Report, Summary for Policymakers, available at: https://www.ipcc.ch/report/ar6/wg1 (last access: 24 November 2021), 2021.

Jiang, X., Guenther, A., Potosnak, M., Geron, C., Seco, R., Karl, T., Kim, S., Gu, L., and Pallardy, S.: Isoprene emission response to drought and the impact on global atmospheric chemistry, Atmos. Environ., 183, 69-83, https://doi.org/10.1016/j.atmosenv.2018.01.026, 2018. 
Kimball, J. S., Jones, L. A., Endsley, A., Kundig, T., and Reichle, R.: SMAP L4 Global Daily 9 km EASE-Grid Carbon Net Ecosystem Exchange, Version 6, NASA National Snow and Ice Data Center Distributed Active Archive Center [data set], Boulder, Colorado USA, https://doi.org/10.5067/L6C9EY1O8VIC, 2021.

Kumar, S. V., Reichle, R. H., Koster, R. D., Crow, W. T., and Peters-Lidard, C. D.: Role of subsurface physics in the assimilation of surface soil moisture observations, J. Hydrometeorol., 10, 1534-1547, https://doi.org/10.1175/2009JHM1134.1, 2009.

Lapina, K., Henze, D. K., Milford, J. B., Huang, M., Lin, M., Fiore, A. M., Carmichael, G., Pfister, G. G., and Bowman, K.: Assessment of source contributions to seasonal vegetative exposure to ozone in the U.S., J. Geophys. Res.-Atmos., 119, 785 324-340, https://doi.org/10.1002/2013JD020905, 2014.

Lawston, P. M., Santanello, J. A., Zaitchik, B. F., and Rodell, M.: Impact of irrigation methods on land surface model spinup and initialization of WRF forecasts, J. Hydrometeor., 16, 1135-1154, https://doi.org/10.1175/JHM-D-14-0203.1, 2015.

Lennartz, S. T., Marandino, C. A., von Hobe, M., Cortes, P., Quack, B., Simo, R., Booge, D., Pozzer, A., Steinhoff, T., Arevalo-Martinez, D. L., Kloss, C., Bracher, A., Röttgers, R., Atlas, E., and Krüger, K.: Direct oceanic emissions unlikely to account for the missing source of atmospheric carbonyl sulfide, Atmos. Chem. Phys., 17, 385-402, https://doi.org/10.5194/acp-17-385-2017, 2017.

795 Lin, M., Malyshev, S., Shevliakova, E., Paulot, F., Horowitz, L. W., Fares, S., Mikkelsen, T. N., and Zhang, L.: Sensitivity of ozone dry deposition to ecosystem-atmosphere interactions: A critical appraisal of observations and simulations, Global Biogeochem. Cy., 33, 1264-1288, https://doi.org/10.1029/2018GB006157, 2019.

Lin, M., Horowitz, L.W., Xie, Y., Paulot, F., Malyshev, S., Shevlickova, E., Finco, A., Gerosa, G., Kubinstin, D., and

Pilegaard, K.: Vegetation feedbacks during drought exacerbate ozone air pollution extremes in Europe, Nat. Clim. Chang., 10, 444-451, https://doi.org/10.1038/s41558-020-0743-y, 2020.

Lombardozzi, D., Levis, S., Bonan, G., Hess, P. G., and Sparks, J. P.: The Influence of Chronic Ozone Exposure on Global Carbon and Water Cycles, J. Climate, 28, 292-305, https://doi.org/10.1175/JCLI-D14-00223.1, 2015.

Mills, G., Buse, A., Gimeno, B., Bemejo, V., Holland, M., Emberson, L., and Pleijel, H.: A synthesis of AOT40-based response functions and critical levels of ozone for agricultural and horticultural crops, Atmos. Environ., 41, 2630-2643, https://doi.org/10.1016/j.atmosenv.2006.11.016, 2007. 
810 Mills, G., Hayes, F., Simpson, D., Emberson, L., Norris, D., Harmens, H., and Büker, P.: Evidence of widespread effects of ozone on crops and (semi-) natural vegetation in Europe (1990-2006) in relation to AOT40-and flux-based risk maps, Global Change Biol., 17, 592-613, https://doi.org/10.1111/j.1365-2486.2010.02217.x, 2011.

Mills, G., Sharps, K., Simpson, D., Pleijel, H., Broberg, M., Uddling, J., Jaramillo, F., Davies, W. J., Dentener, F., van den

815 Berg, M., Agrawal, M., Agrawal, S. B., Ainsworth, E. A., Buker, P., Emberson, L., Feng, Z., Harmens, H., Hayes, F., Kopbayashi, K., Paoletti, E., and Van Dingenen, R.: Ozone pollution will compromise efforts to increase global wheat production, Global Change Biol., 24, 3560-3574, https://doi.org/10.1111/gcb.14157, 2018a.

Mills, G., Pleijel, H., Malley, C. S., Sinha, B., Cooper, O. R., Schultz, M. G., Neufeld, H. S., Simpson, D., Sharps, K., Feng, Z., Gerosa, G., Harmens, H., Kobayashi, K., Saxena, P., Paoletti, E., Sinha, V., Xu, X.: Tropospheric Ozone Assessment Report: Present-day tropospheric ozone distribution and trends relevant to vegetation, Elem. Sci. Anth., 6, 47, https://doi.org/10.1525/elementa.302, 2018b.

Monfreda, C., Ramankutty, N., and Foley, J. A.: Farming the planet: 2. Geographic distribution of crop areas, yields, 825 physiological types, and net primary production in the year 2000, Global Biogeochem. Cycles, 22, GB1022, https://doi.org/10.1029/2007GB002947, 2008.

NASA: ACT-America 2016 1-minute Merged B-200/C-130 Data, Version R1/R4, NASA Langley Research Center Airborne Science Data for Atmospheric Composition [data set], Hampton, Virginia, USA, available at: https://wwwair.larc.nasa.gov/cgi-bin/ArcView/actamerica.2016, last access: 8 November 2021.

NASA Socioeconomic Data and Applications Center: Gridded Population of the World, Version 4.11, Columbia University Center for International Earth Science Information Network [data set], Palisades, New York, USA, https://doi.org/10.7927/H49C6VHW, 2018.

Niu, G. Y., Yang, Z. L., Mitchell, K. E., Chen, F., Ek, M. B., Barlage, M., Kumar, A., Manning, K., Niyogi, D., Rosero, E., Tewari, M., and Xia, Y.: The community Noah land surface model with multiparameterization options (Noah-MP): 1. Model description and evaluation with local-scale measurements, J. Geophys. Res.-Atmos., 116, 1-19, https://doi.org/10.1029/2010JD015139, 2011. 
Niyogi, D. S. and Raman, S.: Comparison of Four Different Stomatal Resistance Schemes Using FIFE Observations, J. Appl. Meteorol. Climatol., 36, 903-917, https://doi.org/10.1175/1520-0450(1997)036\%3C0903:COFDSR\%3E2.0.CO;2, 1997.

Out-Larbi, F., Conte, A., Fares, S., Wild, O., and Ashworth, K.: Current and future impacts of drought and ozone stress on Northern Hemisphere forests, Global Change Biol., 26, 6218-6234, https://doi.org/10.1111/gcb.15339, 2020.

Ronan, A. C., Ducker, J. A., Schnell, J. L., and Holmes, C. D.: Have improvements in ozone air quality reduced ozone uptake into plants? Elem. Sci. Anth., 8, 2, https://doi.org/10.1525/elementa.399, 2020.

Salmon, J. M., Friedl, M. A., Frolking, S., Wisser, D., and Douglas, E. M.: Global rain-fed, irrigated, and paddy croplands: A new high resolution map derived from remote sensing, crop inventories and climate data, Int. J. Appl. Earth Obs., 38, 321334, https://doi.org/10.1016/j.jag.2015.01.014, 2015.

855 Saylor, R. D., Wolfe, G. M., Meyers, T. P., Hicks, B. B.: A corrected formulation of the Multilayer Model (MLM) for inferring gaseous dry deposition to vegetated surfaces, Atmos. Environ., 92, 141-145. https://doi.org/10.1016/j.atmosenv.2014.03.056, 2014.

Silva, S. J. and Heald, C. L.: Investigating dry deposition of ozone to vegetation, J. Geophys. Res.-Atmos., 123, 559-573, https://doi.org/10.1002/2017JD027278, 2018.

Stevenson, D. S., Dentener, F. J., Schultz, M. G., Ellingsen, K., van Noije, T. P. C., Wild, O., Zeng, G., Amann, M., Atherton, C. S., Bell, N., Bergmann, D. J., Bey, I., Butler, T., Cofala, J., Collins, W. J., Derwent, R. G., Doherty, R. M., Drevet, J., Eskes, H. J., Fiore, A. M., Gauss, M., Hauglustaine, D. A., Horowitz, L. W., Isaksen, I. S. A., Krol, M. C., 865 Lamarque, J. F., Lawrence, M. G., Montanaro, V., Müller, J. F., Pitari, G., Prather, M. J., Pyle, J. A., Rast, S., Rodriquez, J. M., Sanderson, M. G., Savage, N. H., Shindell, D. T., Strahan, S. E., Sudo, K., Szopa, S.: Multimodel ensemble simulations of present-day and near-future tropospheric ozone, J. Geophys. Res. Atmos., 111, https://doi.org/10.1029/2005JD006338, 2006.

870 Sweeney, C., Karion, A., Wolter, S., Newberger, T., Guenther, D., Higgs, J. A., Andrews, A. E., Lang, P. M., Neff, D., Dlugokencky, E., Miller, J. B., Montzka, S. A., Miller, B. R., Masarie, K. A., Biraud, S. C., Novelli, P. C., Crotwell, M., Crotwell, A. M., Thoning, K., and Tans, P. P.: Seasonal climatology of $\mathrm{CO}_{2}$ across North America from aircraft measurements in the NOAA/ESRL Global Greenhouse Gas Reference Network, J. Geophys. Res.-Atmos., 120, 5155-5190, https://doi.org/10.1002/2014jd022591, 2015. 
US Environmental Protection Agency: CASTNET Historical Deposition Data, US EPA Office of Atmospheric Programs [data set], Research Triangle Park, North Carolina, USA, available at: https://java.epa.gov/castnet/clearsession.do, last access: 8 November 2021.

880 Val Martin, M., Heald, C. L., and Arnold, S. R.: Coupling dry deposition to vegetation phenology in the Community Earth System Model: Implications for the simulation of surface O3, Geophys. Res. Lett., 41, 2988-2996, https://doi.org/10.1002/2014GL059651, 2014.

Van Dingenen, R., Dentener, F., Raes, F., Krol, M. C., Emberson, L., and Cofala, J.: The global impact of ozone on 885 agricultural crop yields under current and future air quality legislation, Atmos. Environ., 43, 604-618, https://doi.org/10.1016/j.atmosenv.2008.10.033, 2009.

Wesely, M. L.: Parameterization of surface resistances to gaseous dry deposition in regional-scale numerical models, Atmos. Environ., 41, 52-63, https://doi.org/10.1016/j.atmosenv.2007.10.058, 1989.

Whelan, M. E., Anderegg, L. D., Badgley, G., Campbell, J. E., Commane, R., Frankenberg, C., Hilton, T. W., Kuai, L., Parazoo, N., Shiga, Y., Wang, Y., and Worden, J.: Scientific Communities Striving for a Common Cause: Innovations in Carbon Cycle Science, Bull. Amer. Meteor., 101, E1537-E1543, https://doi.org/10.1175/BAMS-D-19-0306.1, 2020.

895 Wu, Z., Schwede, D. B., Vet, R., Walker, J. T., Shaw, M., Staebler, R., and Zhang, L.: Evaluation and Intercomparison of Five North American Dry Deposition Algorithms at a Mixed Forest Site, J. Adv. Model. Earth Sy., 10, 1571-1586, https://doi.org/10.1029/2017MS001231, 2018.

Yang, Z.-L., Niu, G.-Y., Mitchell, K. E., Chen, F., Ek, M. B., Barlage, M., Longuevergne, L., Manning, K., Niyogi, D., 900 Tewari, M., and Xia, Y.: The community Noah land surface model with multiparameterization options (Noah-MP): 2. Evaluation over global river basins, J. Geophys. Res., 116, D12110, https://doi.org/10.1029/2010JD015140, 2011.

Yu, L., Wen, J., Chang, C. Y., Frankenberg, C., and Y. Sun: High Resolution Global Contiguous SIF Estimates Derived from OCO-2 SIF and MODIS, Oak Ridge National Laboratory Distributed Active Archive Center [data set], Oak Ridge, 905 Tennessee, USA, https://doi.org/10.3334/ORNLDAAC/1696, 2019.

Yue, X. and Unger, N.: Ozone vegetation damage effects on gross primary productivity in the United States, Atmos. Chem. Phys., 14, 9137-9153, https://doi.org/10.5194/acp-14-9137-2014, 2014. 
910 Zumkehr, A., Hilton, T. W., Whelan, M. E., Smith, S., Kuai, L., Worden, J., and Campbell, J. E.: Global Gridded Anthropogenic Emissions Inventory of Carbonyl Sulfide, Atmos. Environ., 183, 11-19, https://doi.org/10.1016/j.atmosenv.2018.03.063, 2018.

\section{Tables}

Table 1: Model cases and their configurations relevant to the discussions of this study.

\begin{tabular}{|c|c|c|c|c|c|c|c|}
\hline $\begin{array}{l}\text { Case } \\
\text { name }\end{array}$ & $\begin{array}{l}\text { Land } \\
\text { surface } \\
\text { model }\end{array}$ & $\begin{array}{l}\text { Stomatal } \\
\text { resistance } \\
\text { scheme }\end{array}$ & $\begin{array}{l}\text { SM factor } \\
\text { controlling } \\
R_{s}(\beta)\end{array}$ & $\begin{array}{l}\text { Surface exchange } \\
\text { coefficient for heat } \\
\left(\mathrm{C}_{\mathrm{H}}\right) \text { scheme }\end{array}$ & $\begin{array}{l}\text { Irrigation } \\
\text { scheme }\end{array}$ & $\begin{array}{l}\text { Dry deposition } \\
\text { scheme }\end{array}$ & Note \\
\hline CLM_D & Noah-MP & Ball-Berry & CLM-type & Monin-Obukhov & Sprinkler & Dynamic & $\begin{array}{l}\text { new in } \\
\text { this } \\
\text { study }\end{array}$ \\
\hline
\end{tabular}

Table 2: Dose-response functions used to estimate the LULC- and crop-specific Relative Yield Losses (i.e., 1 - Relative Yield, $\mathrm{RY}$ ) due to $\mathrm{O}_{3}$ exposure and uptake, along with their references.

\begin{tabular}{|c|c|c|c|}
\hline \multirow{2}{*}{$\begin{array}{l}\text { LULC } \\
\text { type }\end{array}$} & \multirow{2}{*}{$\begin{array}{l}\text { Crop } \\
\text { type }\end{array}$} & \multicolumn{2}{|c|}{ Dose-response function (references) } \\
\hline & & $\begin{array}{l}\text { Based on Phytotoxic Ozone Dose above the } \\
\text { critical level } y \text { nmol } \mathrm{m}^{-2} \mathrm{~s}^{-1}\left(\mathrm{POD}_{\mathrm{y}} \text {, in } \mathrm{mmol}\right. \\
\left.\mathrm{m}^{-2}\right)\end{array}$ & Based on AOT40 in ppmh \\
\hline $\begin{array}{l}\text { Deciduous } \\
\text { Forest }\end{array}$ & / & $\mathrm{RY}=-0.0154 \mathrm{POD}_{1}+1.012(\mathrm{CLTRAP}, 2017)$ & / \\
\hline Grasslands & / & $\mathrm{RY}=-0.0074 \mathrm{POD}_{1}+0.982(\mathrm{CLTRAP}, 2017)$ & / \\
\hline Croplands & Wheat & $\begin{array}{l}\mathrm{RY}=-0.0064 \mathrm{POD}_{3}+0.9756 \\
\text { (Mills et al., 2018a; CLTRAP, 2017) }\end{array}$ & $\begin{array}{l}\text { RY }=-0.0161 \text { AOT40 }+0.99 \text { (Mills et al., 2007) } \\
\mathrm{RY}=-0.009 \text { AOT40 }+0.969 \text { (Mills et al., 2018a) }\end{array}$ \\
\hline
\end{tabular}


Table 3: Evaluation of daily-averaged WRF-Chem gross primary productivity and evaporative fraction.

\begin{tabular}{|c|c|c|c|c|c|c|c|c|}
\hline \multirow{3}{*}{$\begin{array}{l}\text { Flux/weather } \\
\text { variables (unit) }\end{array}$} & \multirow{3}{*}{$\begin{array}{l}\text { LULC } \\
\text { type }\end{array}$} & \multirow[t]{3}{*}{ Observation(-derived) } & \multicolumn{6}{|c|}{ Model case } \\
\hline & & & \multicolumn{2}{|c|}{ Noah_D } & \multicolumn{2}{|c|}{ CLM_D } & \multicolumn{2}{|c|}{ P1_W } \\
\hline & & & No DA & DA & No DA & DA & No DA & DA \\
\hline \multirow{3}{*}{$\begin{array}{l}\text { Gross primary } \\
\text { productivity } \\
\left(\mathrm{g} \mathrm{m}^{-2} \mathrm{~d}^{-1}\right)\end{array}$} & forests & 7.39 & 7.88 & 7.08 & 9.06 & 6.94 & \multirow{3}{*}{\multicolumn{2}{|c|}{ I }} \\
\hline & shrub/grass & 5.11 & 3.28 & 3.29 & 4.74 & 3.89 & & \\
\hline & croplands & 8.94 & 7.64 & 7.40 & 9.77 & 8.13 & & \\
\hline \multirow{3}{*}{$\begin{array}{l}\text { Evaporative } \\
\text { fraction }\end{array}$} & forests & 0.75 & 0.65 & 0.60 & 0.67 & 0.60 & 0.66 & 0.63 \\
\hline & shrub/grass & 0.67 & 0.53 & 0.58 & 0.57 & 0.61 & 0.48 & $0.48^{\mathrm{a}}$ \\
\hline & croplands & 0.79 & 0.67 & $0.67^{\mathrm{a}}$ & 0.71 & 0.68 & 0.63 & 0.62 \\
\hline
\end{tabular}

${ }^{\mathrm{a}}$ The increases from no-DA cases, which led to improved model performance, are $<0.005$.

Table 4: The $24 \mathrm{~h}$ and daytime mean $\mathrm{O}_{3}$ deposition velocity $\left(V_{d}\right)$ and flux $\left(F_{t}\right)$ for three LULC groups.

\begin{tabular}{|c|c|c|c|c|c|c|c|c|}
\hline \multirow{2}{*}{$\begin{array}{l}\text { LULC } \\
\text { type/Model } \\
\text { case }\end{array}$} & \multicolumn{2}{|c|}{ Noah_D } & \multicolumn{2}{|c|}{ CLM_D } & \multicolumn{2}{|c|}{ Noah_W } & \multicolumn{2}{|l|}{ P1_W } \\
\hline & No DA & DA & No DA & DA & No DA & DA & No DA & DA \\
\hline & \multicolumn{8}{|c|}{$24 \mathrm{~h}$ mean $\mathrm{V}_{\mathrm{d} \text { [ozone] }}\left(\mathrm{cm} \mathrm{s}^{-1}\right)$} \\
\hline Forests & 0.64 & 0.56 & 0.68 & 0.51 & 0.54 & 0.53 & 0.49 & 0.48 \\
\hline Shrub/Grass & 0.48 & 0.45 & 0.53 & 0.45 & 0.47 & 0.48 & 0.46 & 0.46 \\
\hline \multirow[t]{2}{*}{ Croplands } & 0.62 & 0.54 & 0.67 & 0.54 & 0.58 & 0.58 & 0.56 & 0.56 \\
\hline & \multicolumn{8}{|c|}{$24 \mathrm{~h}$ mean $\mathrm{F}_{\mathrm{t} \text { [ozone] }}\left(\mathrm{nmol} \mathrm{m}^{-2} \mathrm{~s}^{-1}\right)$} \\
\hline Forests & 7.11 & 6.38 & 7.47 & 6.35 & 6.31 & 6.24 & 5.75 & 5.68 \\
\hline Shrub/Grass & 4.79 & 4.48 & 5.21 & 4.54 & 4.76 & 4.79 & 4.62 & 4.63 \\
\hline \multirow[t]{2}{*}{ Croplands } & 6.90 & 6.11 & 7.39 & 6.06 & 6.69 & 6.64 & 6.44 & 6.42 \\
\hline & \multicolumn{8}{|c|}{ Daytime mean $V_{\mathrm{d}[\text { ozone }]}\left(\mathrm{cm} \mathrm{s}^{-1}\right)$} \\
\hline Forests & 0.94 & 0.80 & 1.02 & 0.71 & 0.79 & 0.77 & 0.70 & 0.69 \\
\hline Shrub/Grass & 0.63 & 0.56 & 0.72 & 0.58 & 0.61 & 0.63 & 0.58 & 0.58 \\
\hline \multirow[t]{2}{*}{ Croplands } & 0.88 & 0.74 & 0.99 & 0.73 & 0.83 & 0.83 & 0.80 & 0.79 \\
\hline & \multicolumn{8}{|c|}{ Daytime mean $\mathrm{F}_{\mathrm{t}[\text { ozone] }}\left(\mathrm{nmol} \mathrm{m}^{-2} \mathrm{~s}^{-1}\right)$} \\
\hline Forests & 11.51 & 10.04 & 12.25 & 8.99 & 10.05 & 9.93 & 9.04 & 8.88 \\
\hline Shrub/Grass & 6.91 & 6.32 & 7.77 & 6.43 & 6.83 & 6.99 & 6.52 & 6.49 \\
\hline Croplands & 10.99 & 9.42 & 12.04 & 9.31 & 10.61 & 10.57 & 10.17 & 10.07 \\
\hline
\end{tabular}


Table 5: Soil moisture and surface fluxes at two CASTNET sites shown in Figure 1d.

\begin{tabular}{|c|c|c|c|c|}
\hline \multirow{2}{*}{$\begin{array}{l}\text { CASTNET sites (soil type; LULC type) } \\
\text { Modeled soil moisture initial condition, column-averaged }\left(\mathrm{m}^{3} \mathrm{~m}^{-3}\right)\end{array}$} & \multicolumn{2}{|c|}{\begin{tabular}{|l|} 
SUM156, Florida \\
(sand; forest)
\end{tabular}} & \multicolumn{2}{|c|}{$\begin{array}{l}\text { PED108, Virginia } \\
\text { (loam; forest) }\end{array}$} \\
\hline & No DA & $\mathrm{DA}$ & No DA & $\mathrm{DA}$ \\
\hline Noah_D & 0.15 & 0.12 & 0.22 & 0.20 \\
\hline CLM D & 0.16 & 0.12 & 0.20 & 0.18 \\
\hline SMAP L4C gross primary productivity $\left(\mathrm{g} \mathrm{m}^{-2} \mathrm{~d}^{-1}\right)$ & \multicolumn{2}{|l|}{7.30} & \multicolumn{2}{|l|}{8.10} \\
\hline Modeled gross primary productivity $\left(\mathrm{g} \mathrm{m}^{-2} \mathrm{~d}^{-1}\right)$ & No DA & $\mathrm{DA}$ & No DA & $\mathrm{DA}$ \\
\hline Noah D & 4.70 & 3.83 & 7.42 & 5.45 \\
\hline CLM D & 5.84 & 5.88 & 10.10 & 4.51 \\
\hline CASTNET (MLM-calculated) daytime $\mathrm{V}_{\mathrm{d}[\mathrm{ozone}]}\left(\mathrm{cm} \mathrm{s}^{-1}\right)$ & \multicolumn{2}{|l|}{0.39} & \multicolumn{2}{|l|}{0.39} \\
\hline Modeled daytime $\mathrm{V}_{\mathrm{d}[\mathrm{ozone}]}\left(\mathrm{cm} \mathrm{s}^{-1}\right)$ & No DA & DA & No DA & DA \\
\hline Noah D & 0.70 & 0.66 & 0.89 & 0.68 \\
\hline CLM D & 0.74 & 0.75 & 1.07 & 0.52 \\
\hline Noah W & 0.63 & 0.62 & 0.82 & 0.79 \\
\hline CASTNET daytime $\mathrm{F}_{\mathrm{t} \text { [ozone] }}\left(\mathrm{nmol} \mathrm{m}^{-2} \mathrm{~s}^{-1}\right)$ & \multicolumn{2}{|l|}{8.67} & \multicolumn{2}{|l|}{11.66} \\
\hline Modeled daytime $\mathrm{F}_{\mathrm{t} \text { [ozone] }}\left(\mathrm{nmol} \mathrm{m}^{-2} \mathrm{~s}^{-1}\right)$ & No DA & DA & No DA & DA \\
\hline Noah D & 17.95 & 17.15 & 30.59 & 24.27 \\
\hline CLM D & 18.85 & 18.93 & 35.63 & 19.24 \\
\hline Noah W & 16.90 & 16.48 & 29.44 & 28.09 \\
\hline
\end{tabular}


Figures

Grouped land use/cover type

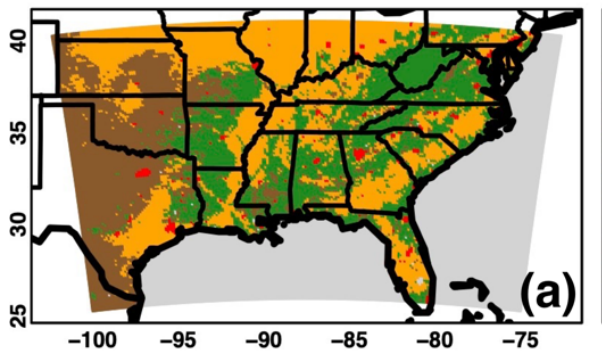

\section{- Water
- Urban}

Croplands

Shrub/Grass

Forests

\section{Population density in $2015\left(\mathrm{~km}^{-2}\right)$}

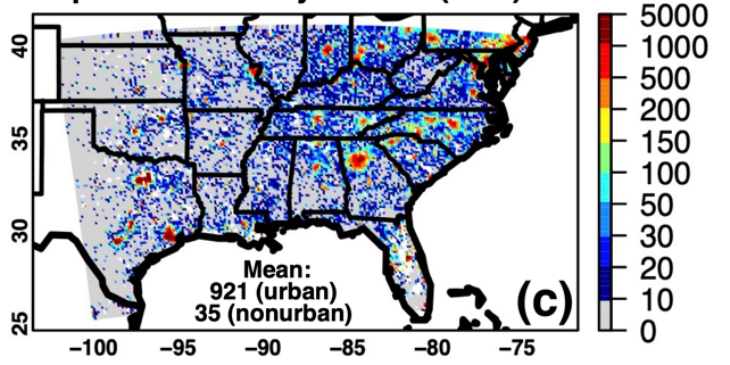

\section{Crop type}

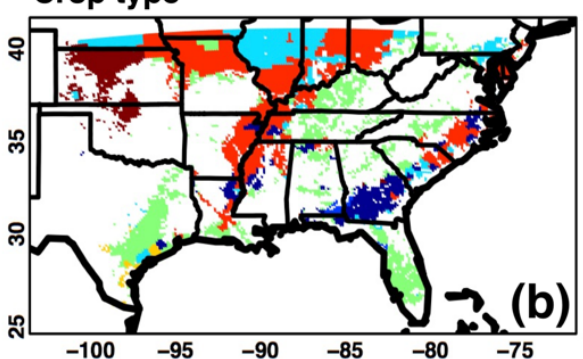

Grouped soil type

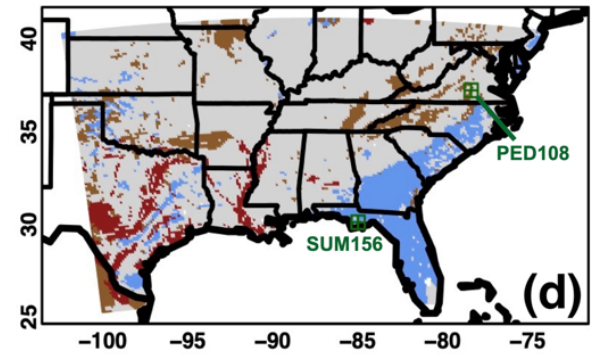

-Wheat

-Soybean

-Sorghum

-Others

-Maize

-Groundnut

-Cotton

Figure 1: (a) Grid-dominant land use/land cover types grouped from the original 20-category model input (Figure 1c in Huang et al., 2021) based on the method in Table S1; (b) grid-dominant crop type over cropland-dominant regions; (c) gridded population density in 2015; (d) highlighted grid-dominant soil types of sand/loamy sand, loam, and clay which are most relevant to discussions in this paper. The original soil type input from the State Soil Geographic database is shown in Figure S1 in Huang et al. (2021). Locations of the two CASTNET sites for the case studies are denoted in green.
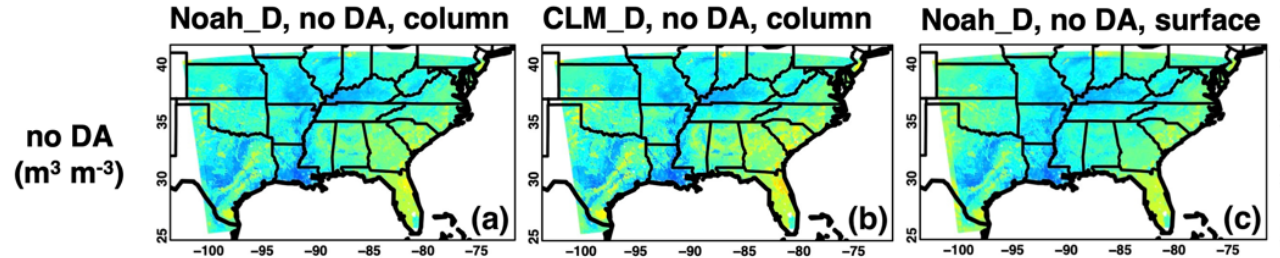

CLM_D, no DA, surface
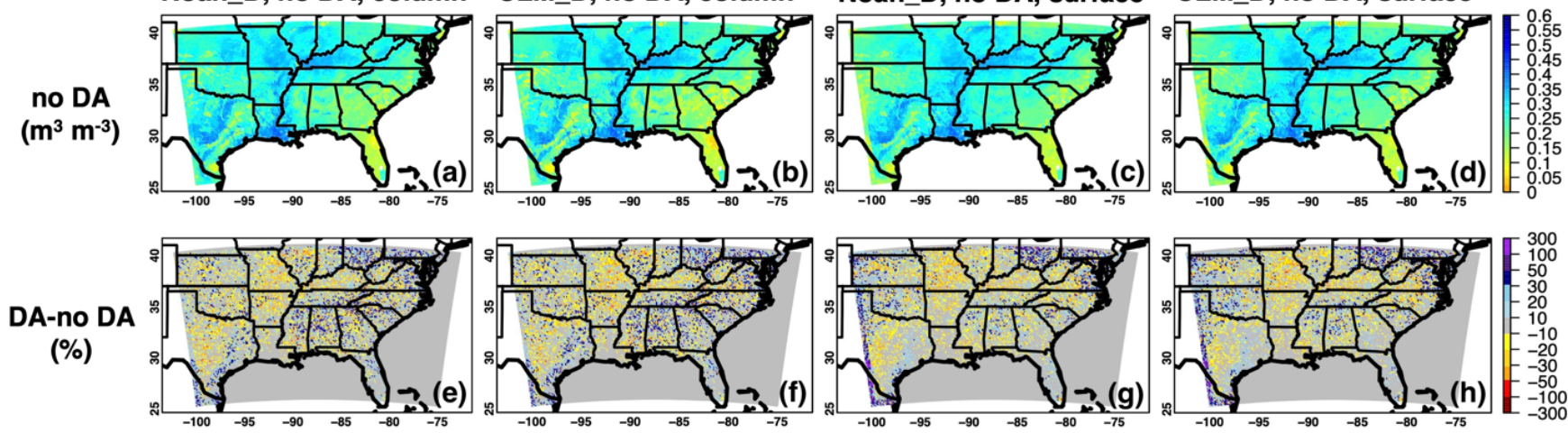

Figure 2: Period-mean (16-28 August 2016) WRF-Chem (a-b) column-averaged and (c-d) surface-layer soil moisture fields at initial times and (e-h) their relative changes in \% due to the SMAP DA. Results based on the Noah_D and CLM_D cases are shown in $(\mathrm{a} ; \mathrm{c} ; \mathrm{e} ; \mathrm{g})$ and $(\mathrm{b} ; \mathrm{d} ; \mathbf{f} ; \mathrm{h})$, respectively. 
SMAP/Copernicus-derived

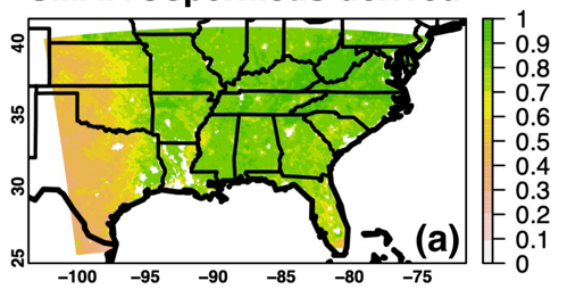

SMAP AM VOD

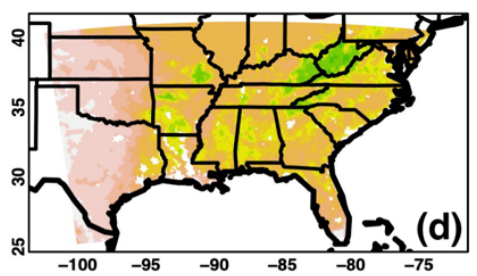

Noah_D, no DA

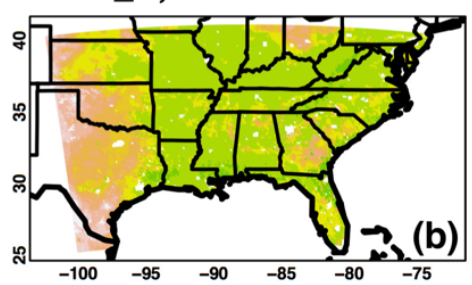

CLM_D, no DA
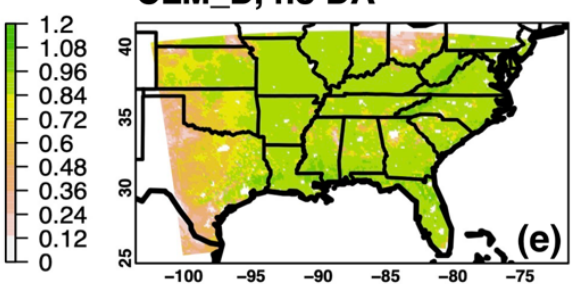

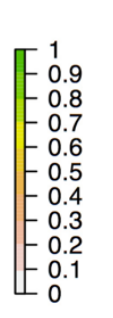

Noah_D, DA-no DA

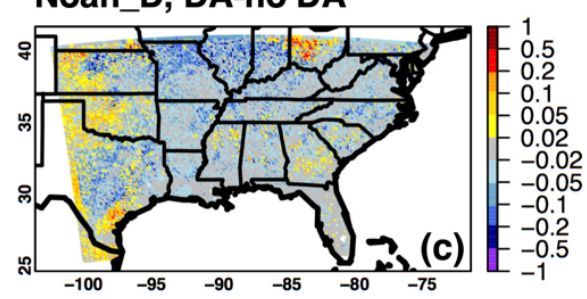

CLM_D, DA-no DA

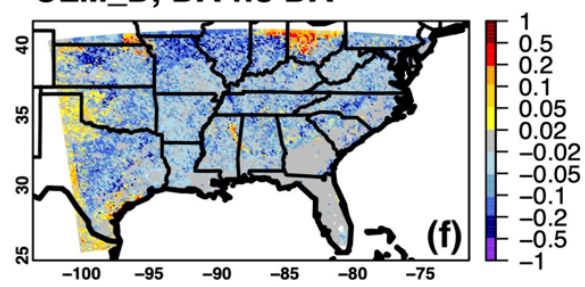

Figure 3: Period-mean (16-28 August 2016) green vegetation fraction (a) derived from the Copernicus Global Land Service product and the SMAP morning-time (AM) vegetation optical depth (VOD) using the method described in

945 Figure S2; (b;c;e;f) based on WRF-Chem calculations as well as their responses to the SMAP DA. Results from the Noah_D and CLM_D cases are shown in (b-c) and (e-f), respectively. Period-mean SMAP AM VOD is shown in (d).

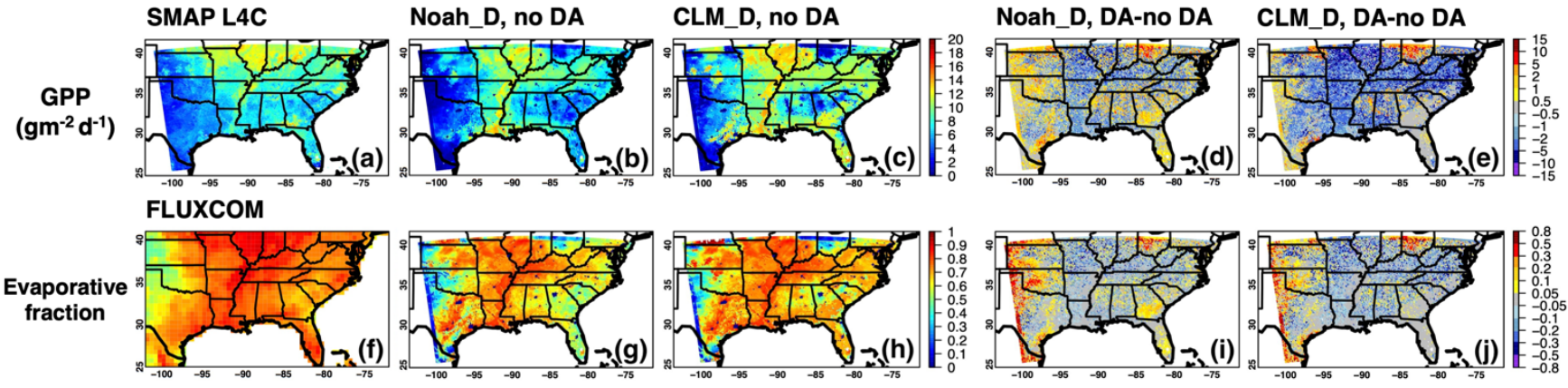

Figure 4: Period-mean (16-28 August 2016) WRF-Chem calculated (b-e) gross primary productivity (GPP); and (g-j) evaporative fraction as well as their responses to the SMAP DA. Results based on the Noah_D and CLM_D cases are shown in $(b ; g ; d ; i)$ and $(c ; h ; e ; j)$, respectively. Period-mean SMAP L4C GPP and FLUXCOM evaporative fraction are shown in (a;f), which are also used to evaluate the model results (Table 3 ). 

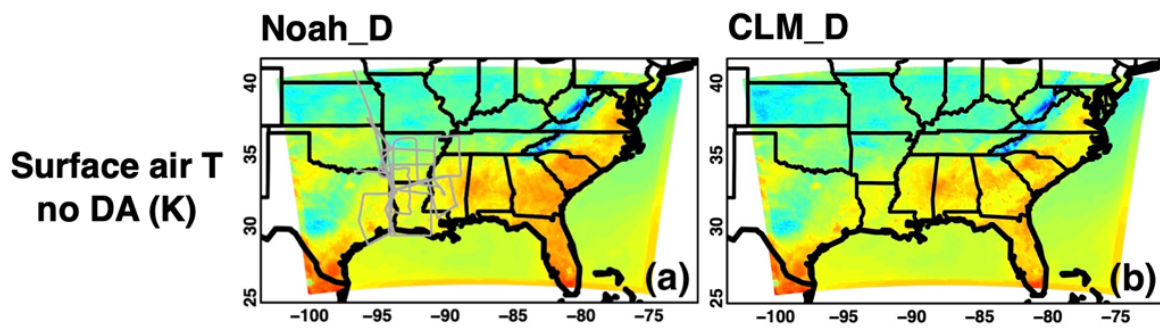

\section{P1_W}
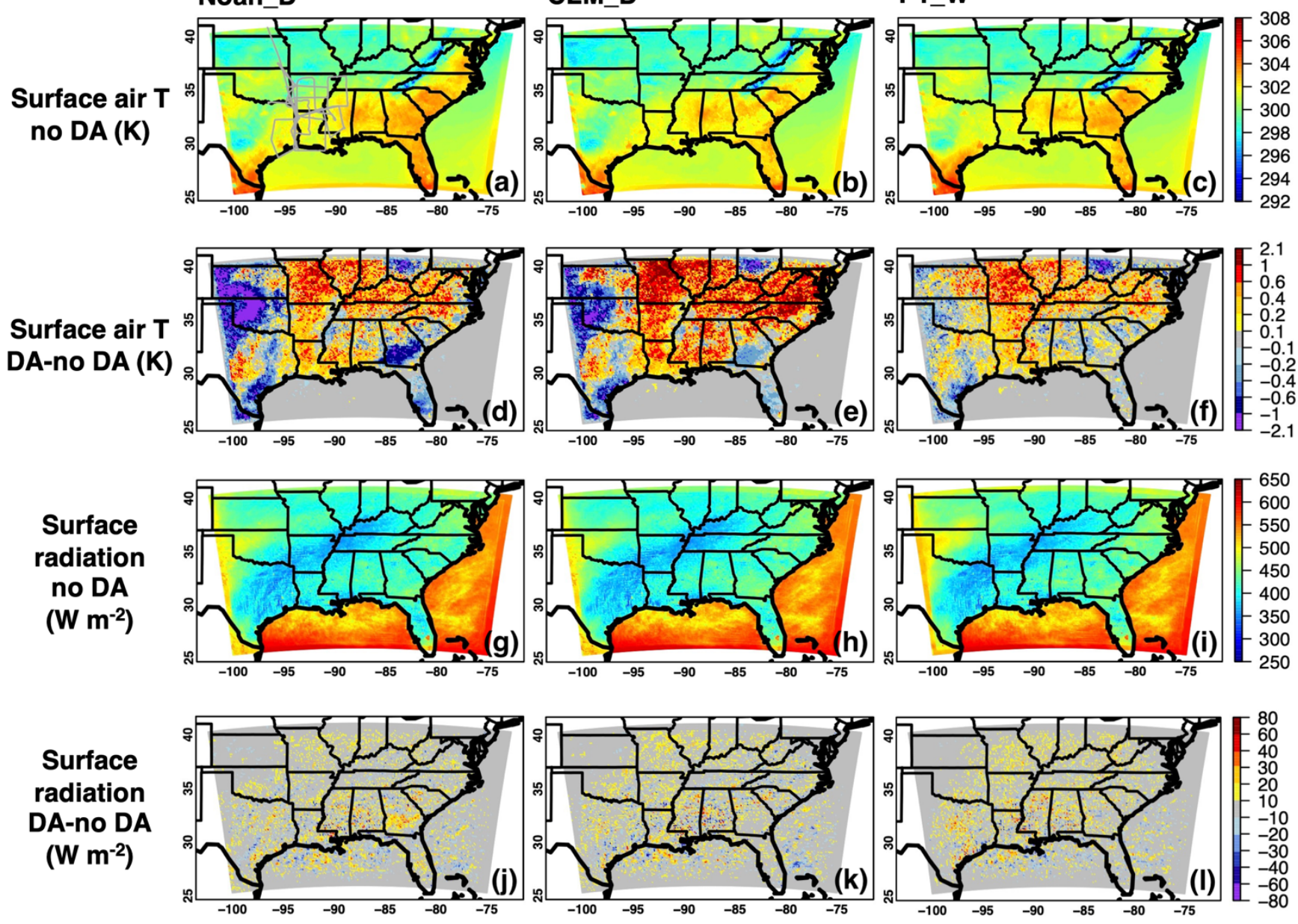

Figure 5: Period-mean (16-28 August 2016) WRF-Chem calculated daytime (a-c) surface air temperature and (g-i)

surface radiation as well as (d-f;j-l) their responses to the SMAP DA. Results based on the Noah_D, CLM_D, and P1_W cases are shown in $(a ; d ; g ; j),(b ; e ; h ; k)$, and $(c ; f ; i ; l)$, respectively. Overall, the weather fields from Noah_D and Noah_W (not shown in figures) cases are nearly the same. Grey lines in (a) indicate the B-200 flight paths over the southeastern US during the 2016 ACT-America campaign. 

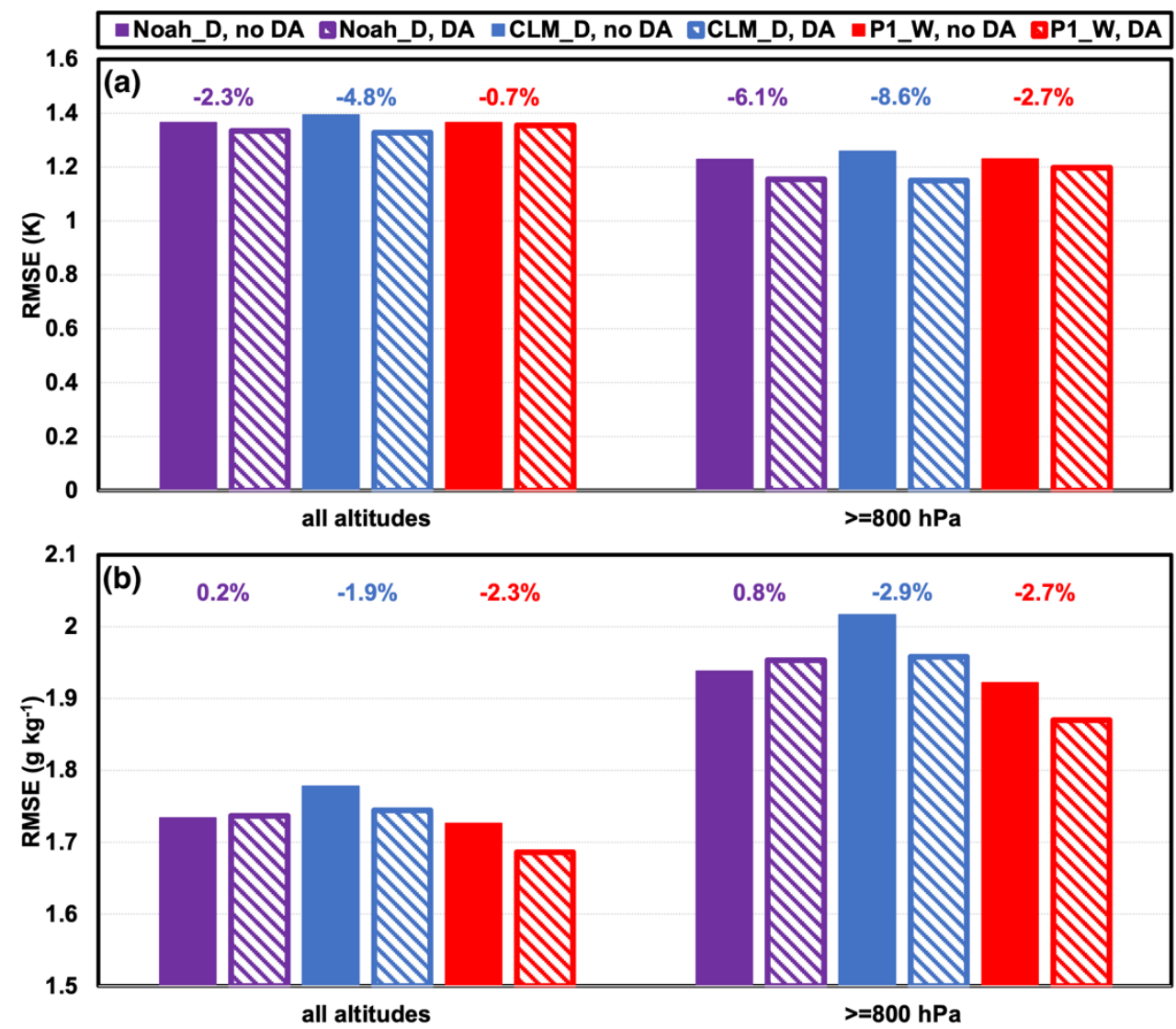

Figure 6: Evaluation of (a) air temperature and (b) water vapor mixing ratios from several WRF-Chem simulations with the B-200 aircraft observations during the 2016 ACT-America campaign. The RMSEs are summarized in barplots based on model comparisons against observations at all altitudes and near the surface $(\geq 800 \mathrm{hPa}$ ).

965 Colored texts above the barplots indicate the SMAP DA impacts on RMSEs. The B200 flight paths are indicated in Figure $5 \mathrm{a}$. 

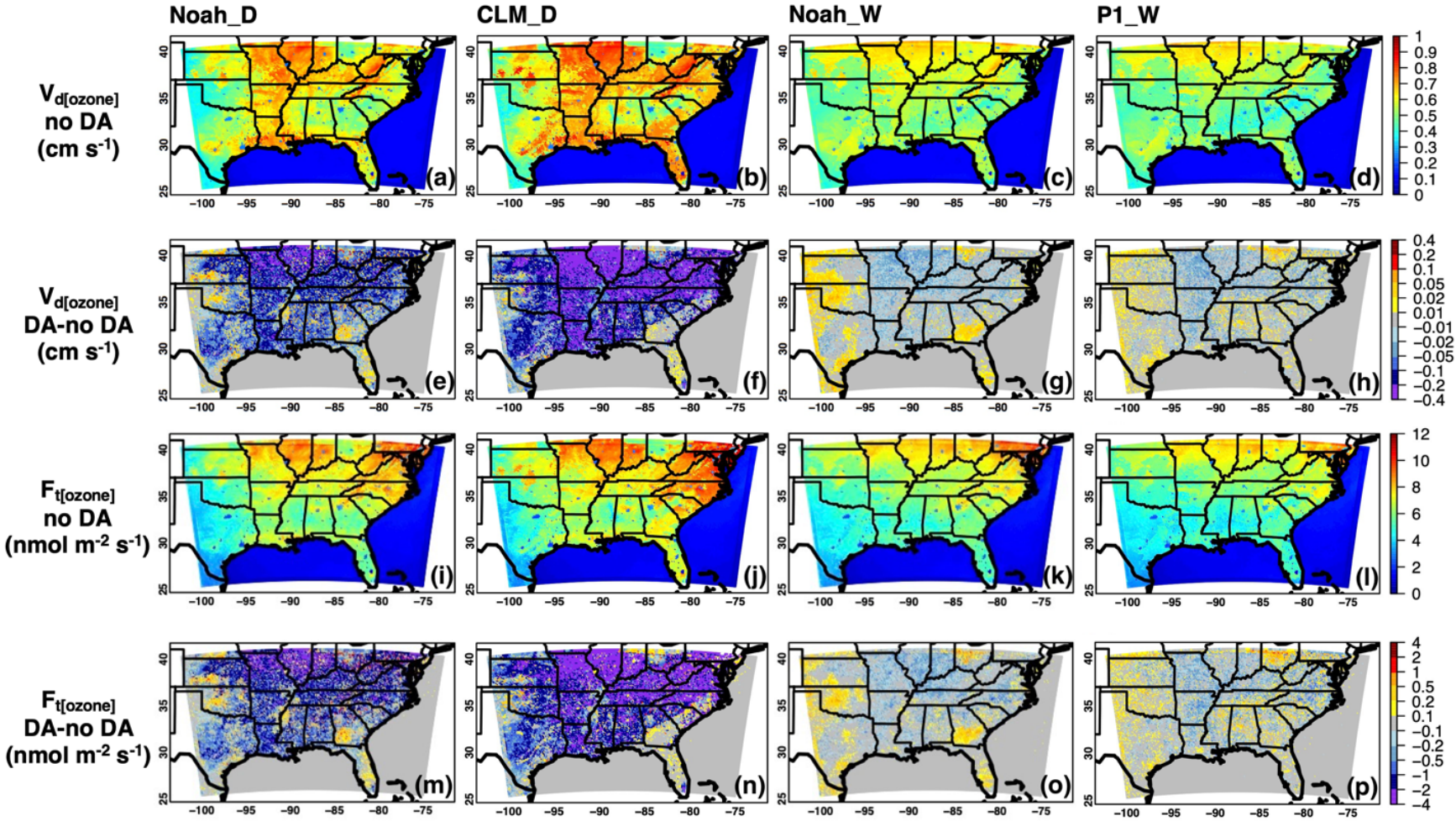

Figure 7: Period-mean (16-28 August 2016) WRF-Chem (a-d) $\mathrm{O}_{3}$ dry deposition velocity and (i-I) $\mathrm{O}_{3}$ dry deposition

flux, as well as (e-h; m-p) the impacts of SMAP DA on these model fields. Results are shown for (a;e;i;m) Noah_D, (b;f;j;n) CLM_D, (c;g;k;o) Noah_W, and (d;h;l;p) P1_W cases, averaged throughout the day. 


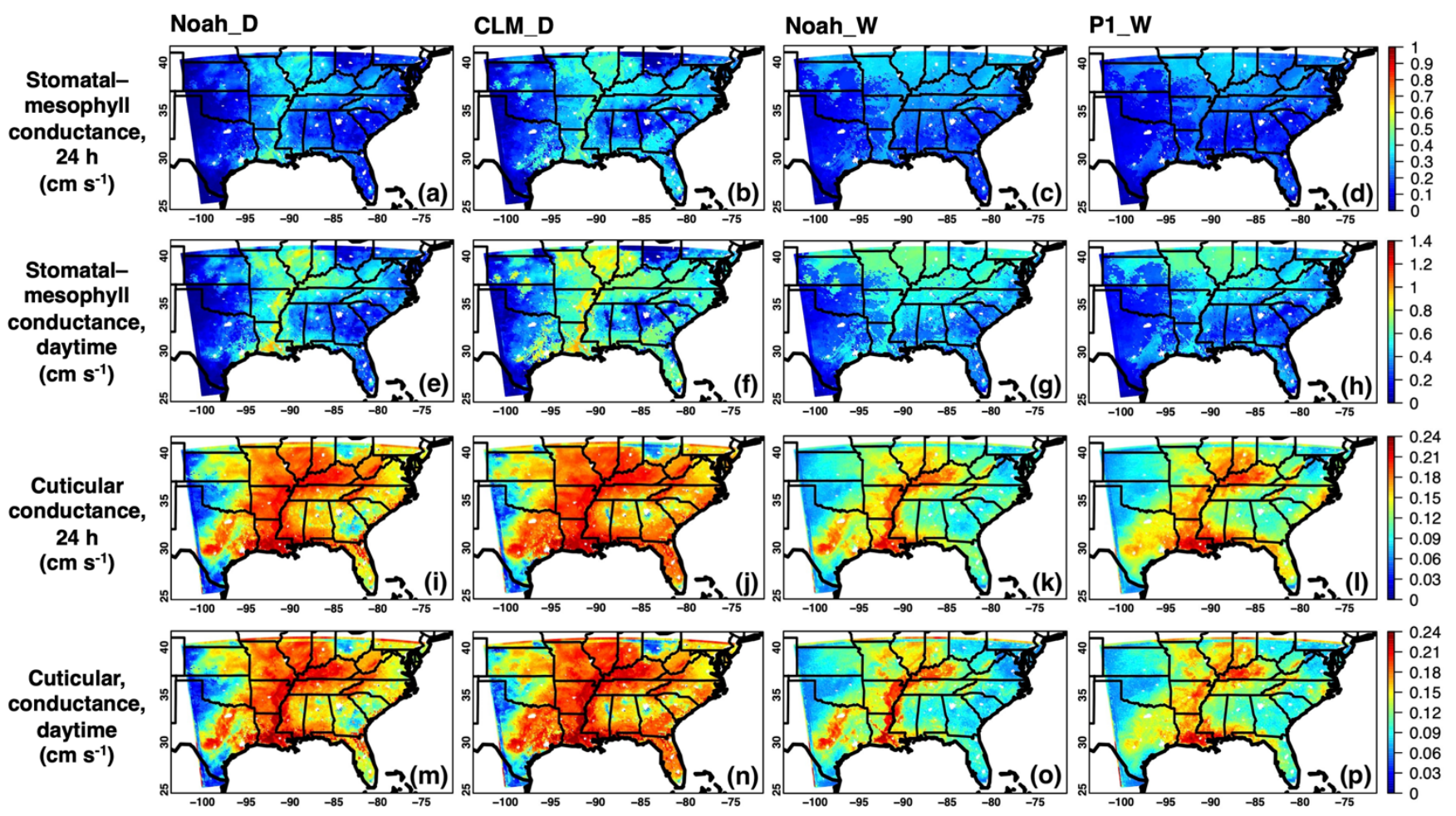

975 Figure 8: Period-mean (16-28 August 2016) WRF-Chem (a-h) stomatal-mesophyll and (i-p) cuticular conductances over non-urban terrestrial regions. Results are shown for (a;e;i;m) Noah_D, (b;f;j;n) CLM_D, (c;g;k;o) Noah_W, and (d;h;l;p) P1_W no-DA cases, averaged (a-d;i-l) throughout the day and (e-h;m-p) during the daytime.
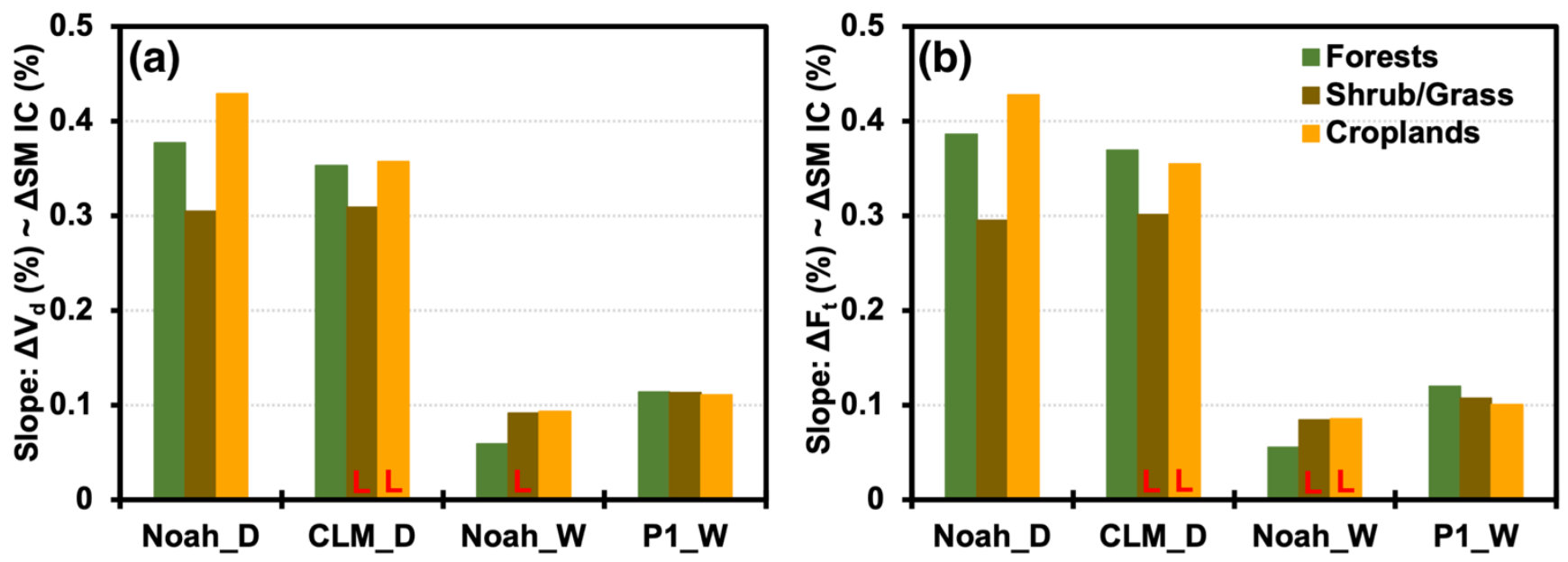

980 Figure 9: Regression slopes of relative changes of (a) $\mathbf{O}_{3}$ dry deposition velocity and (b) $\mathrm{O}_{3}$ dry deposition flux versus the relative changes of column-averaged soil moisture initial conditions due to the SMAP DA, summarized by three LULC groups for all model cases listed in Table 1. The red "L"s indicate the regression analyses with low correlation (i.e., $r$ values of $0.39-0.49$ ). The $p$ values for all regression analyses are $<<0.01$. 

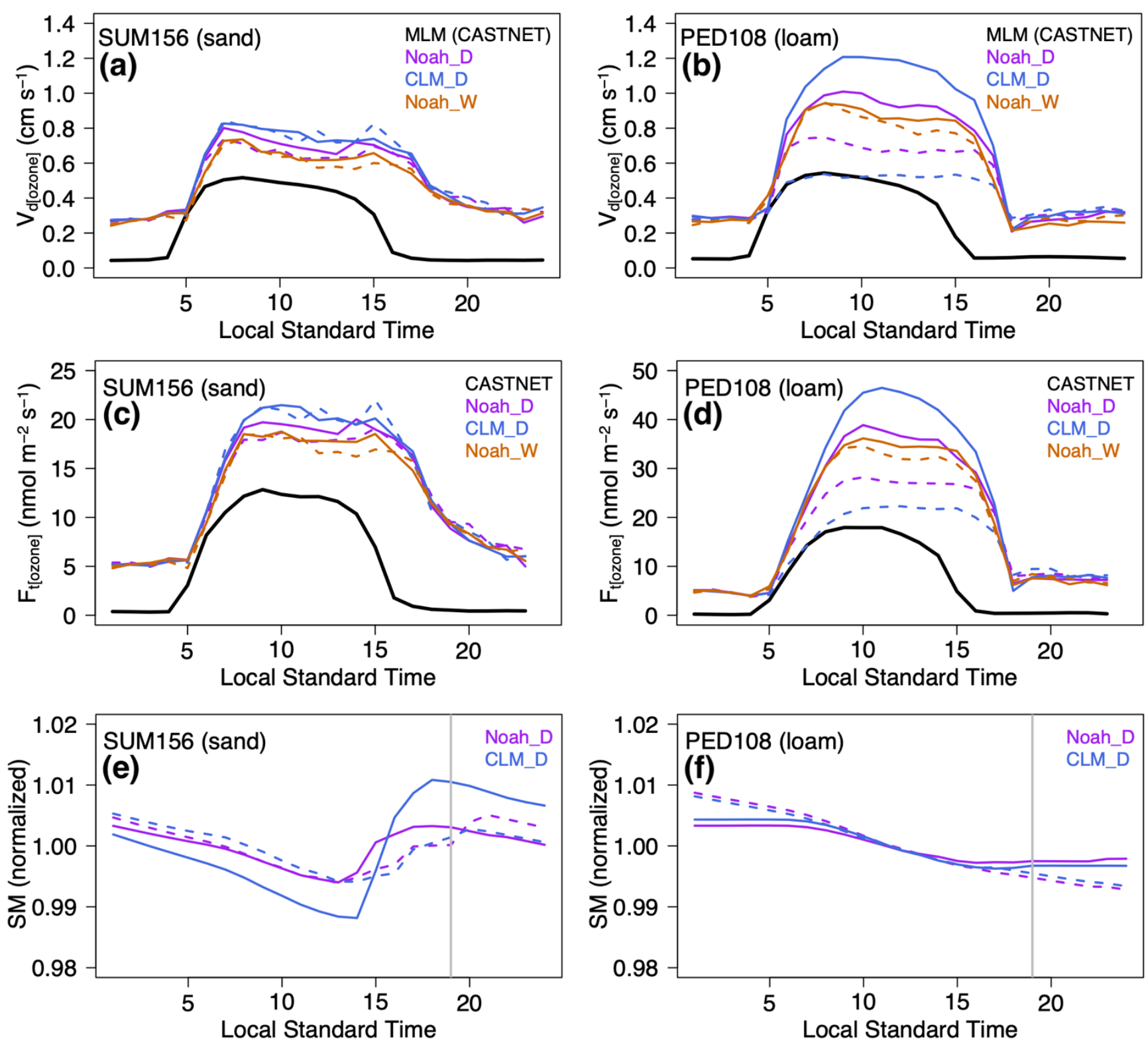

Figure 10: Period-mean (16-28 August 2016) diurnal cycles of (a-b) $\mathrm{O}_{3}$ dry deposition velocity and (c-d) $\mathrm{O}_{3}$ dry deposition flux based on the CASTNET dataset (in black solid lines) and their WRF-Chem counterparts (in purple, blue and brown lines) at the (a;c) SUM156 and (b;d) PED108 sites whose locations are shown in Figure 1d. (e-f) indicate the diurnal variability of WRF-Chem column-averaged soil moisture (normalized) at these two sites, and grey vertical lines denote the initial times of WRF-Chem. Results from the no-DA and DA cases are indicated in solid and dashed lines, respectively. 


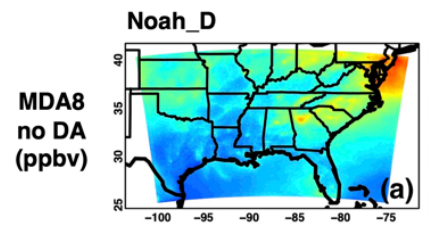

CLM_D

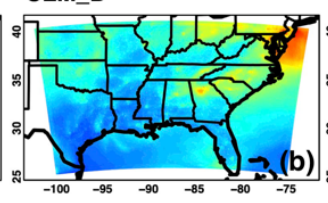

Noah_W

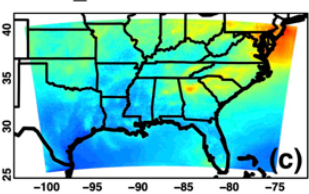

P1_W

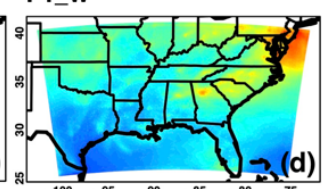

Observed (ppbv)

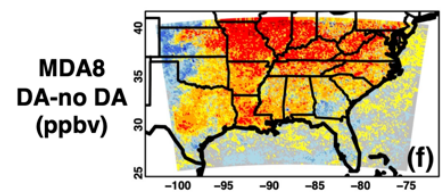

Noah_D-P1_W

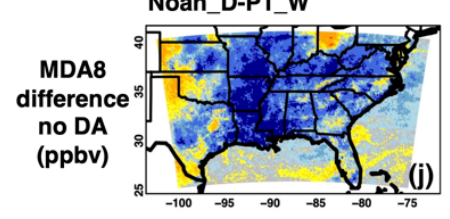

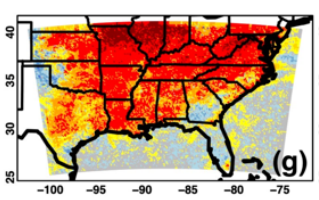

CLM_D-P1_W

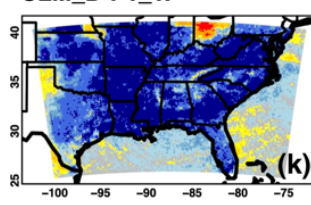

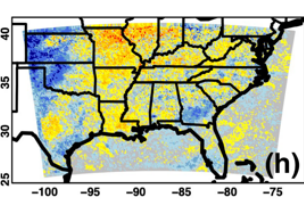

Noah_W-P1_W

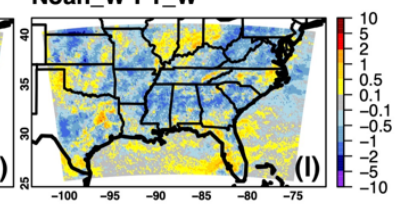

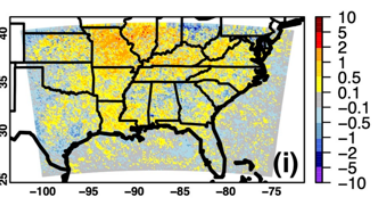

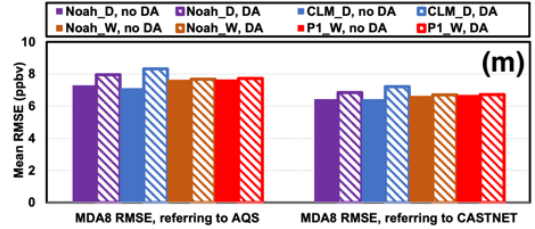

995 Figure 11: Period-mean (16-28 August 2016) (e) observed and modeled (a-d) surface $\mathrm{MDA8}_{3} \mathrm{O}_{3}$ fields and (f-i) their responses to the SMAP DA. Results based on the Noah_D, CLM_D, Noah_W, and P1_W cases are shown in (a;f), $(b ; g),(c ; h)$ and $(d ; i)$, respectively, and the differences between the Noah-MP related cases and the P1_W case are shown in (j-l). Mean MDA8 RMSEs from various cases referring to surface observations are summarized in $(\mathrm{m})$. 

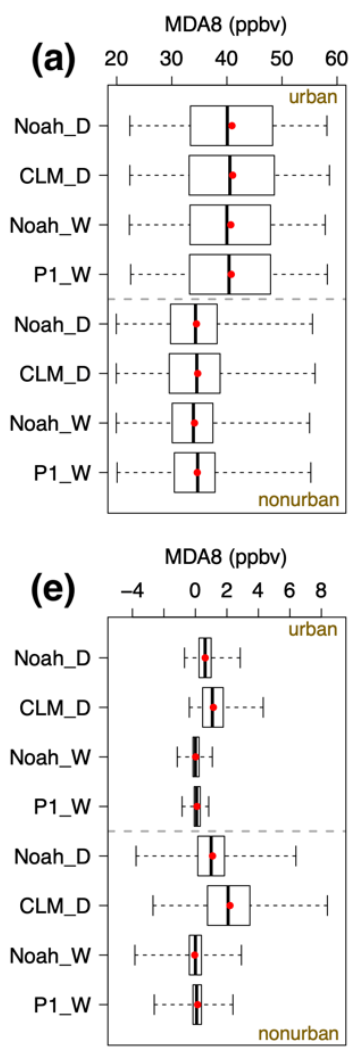
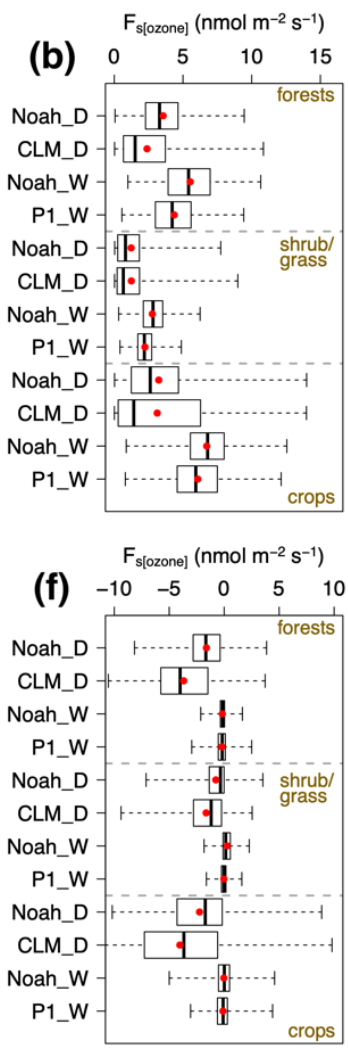
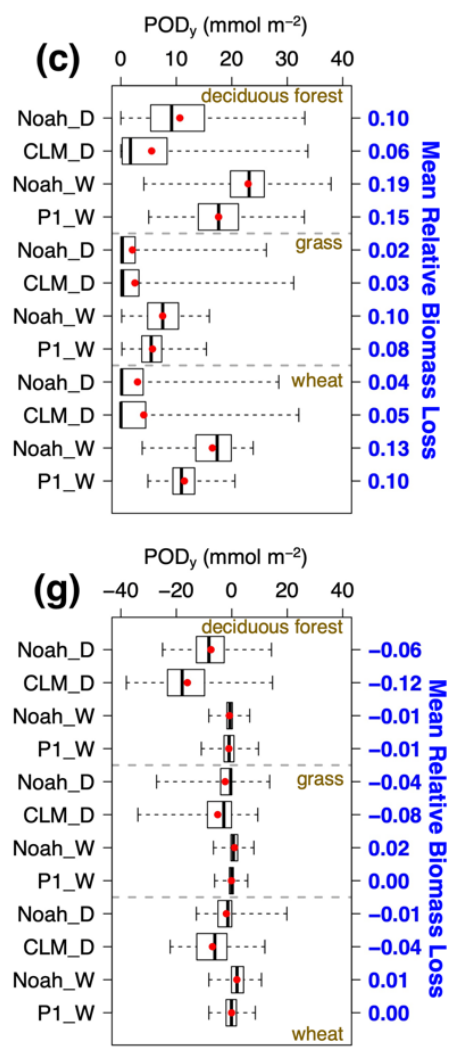

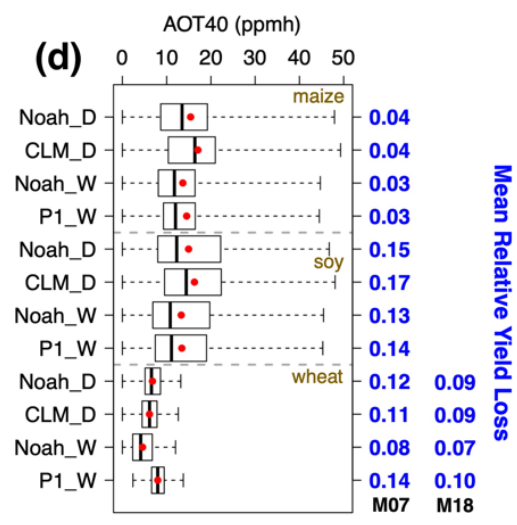

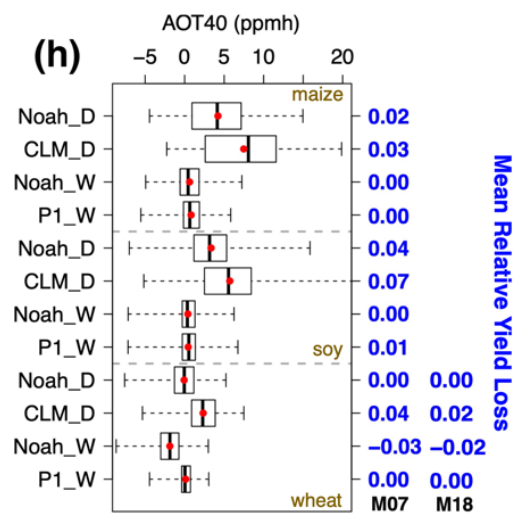

Figure 12: Box-and-whisker plots of WRF-Chem (a) $\mathrm{MDAs}_{3}$; (b) daytime stomatal $\mathrm{O}_{3}$ uptake $\mathrm{F}_{\mathrm{s}[\mathrm{ozone}]}$; (c) derived POD $_{y}$; and (d) derived AOT40, summarized by LULC and crop types from all DA-enabled cases. The impacts of the SMAP DA on these model fields are shown in (e-h). Red filled circles indicate the mean values. The mean relative biomass/crop yield losses estimated based on all DA-enabled cases, as well as the SMAP DA impacts on these values, are included in (c-d;g-h) in blue text. The crop yield losses for wheat, estimated based on the derived AOT40 and two dose-response functions (M07: Mills et al., 2007; M18: Mills et al., 2018a) are included in (d;h).
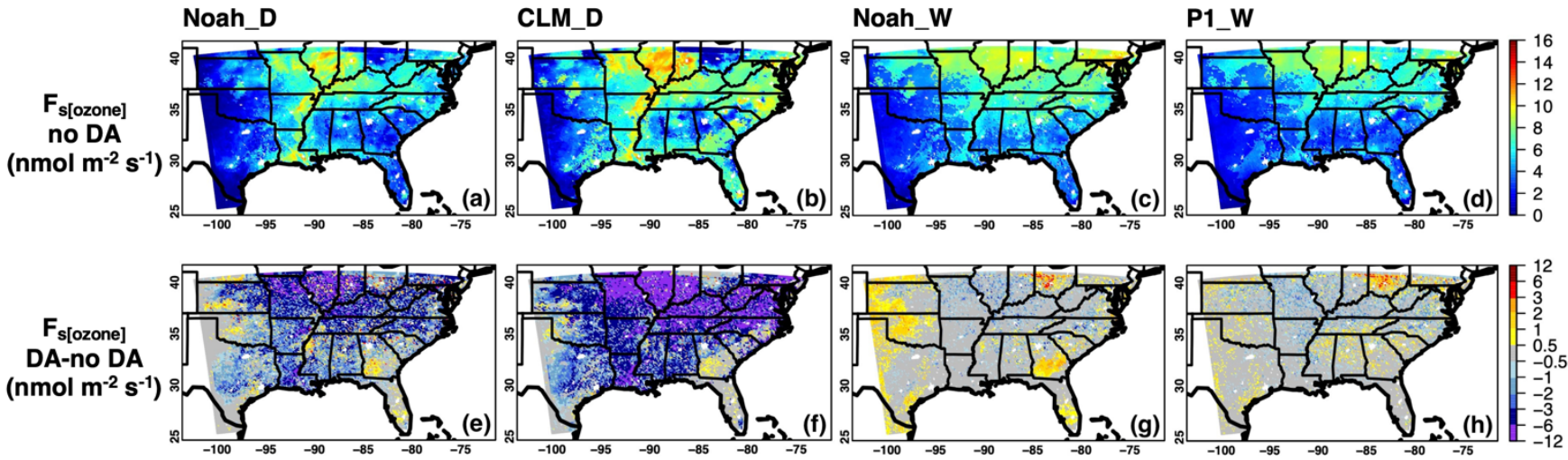

Figure 13: Period-mean (16-28 August 2016) WRF-Chem (a-d) daytime stomatal $O_{3}$ uptake $F_{s[0 z o n e]}$ fields over nonurban terrestrial regions and (e-h) their responses to the SMAP DA. Results based on the (a;e) Noah_D, (b;f) CLM_D, (c;g) Noah_W, and (d;h) P1_W cases are shown. 

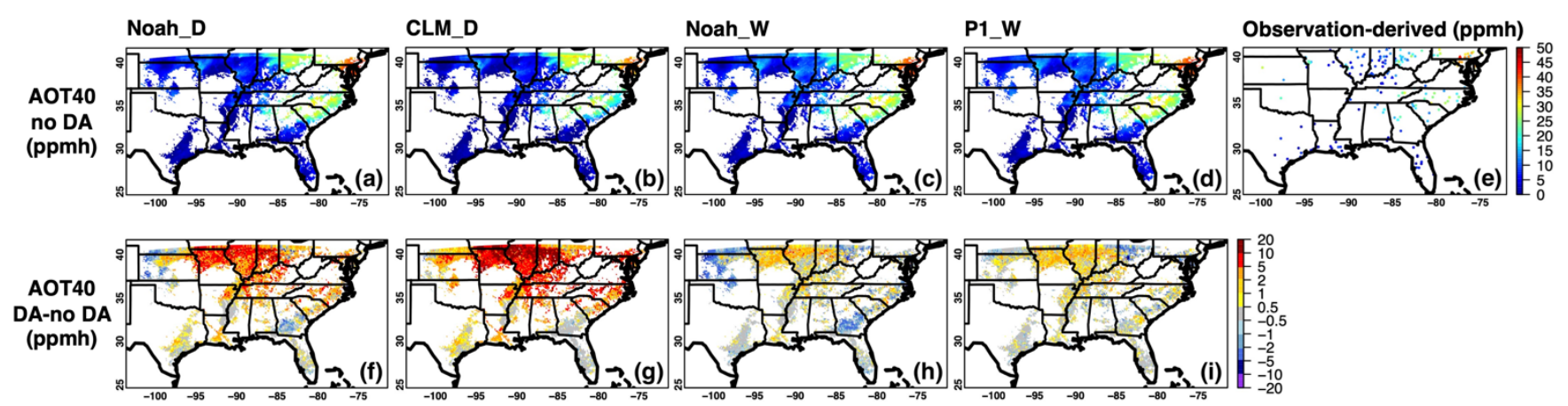

Figure 14: AOT40 in cropland-dominant model grids, derived from surface $\mathrm{O}_{3}$ fields during 16-28 August 2016: (e) indicates the observation-derived, and those based on WRF-Chem results as well as their responses to the SMAP DA from the Noah_D, CLM_D, Noah_W, and P1_W cases are shown in $(a ; f),(b ; g),(c ; h)$, and $(d ; i)$, respectively. 